Cipango Cahiers d'études japonaises

23 | 2020

Charbon et communautés minières au Japon

\title{
La critique de la modernisation du Japon chez Maruyama Masao : assistance au tennō, ultranationalisme et fascisme dans les essais des années 1946-1949
}

Maruyama Masao's Modernization Process Criticism: Imperial Aid, Fascism and Ultra-nationalism in 1946-1949 Essays

\section{Brice Fauconnier}

\section{(2penEdition}

\section{Journals}

Édition électronique

URL : https://journals.openedition.org/cipango/3927

DOI : 10.4000/cipango.3927

ISSN : 2260-7706

Éditeur

INALCO

Édition imprimée

Date de publication : 1 juillet 2020

ISBN : 9782858313426

ISSN : 1164-5857

Référence électronique

Brice Fauconnier, « La critique de la modernisation du Japon chez Maruyama Masao : assistance au tennō, ultranationalisme et fascisme dans les essais des années 1946-1949 », Cipango [En ligne], 23 | 2020, mis en ligne le 16 juin 2020, consulté le 30 juin 2021. URL : http://journals.openedition.org/ cipango/3927; DOI : https://doi.org/10.4000/cipango.3927 


\title{
La critique de la modernisation du Japon chez Maruyama Masao : assistance au tennō, ultranationalisme et fascisme dans les essais des années 1946-1949
}

\author{
Maruyama Masao's Modernization Process Criticism: \\ Imperial Aid, Fascism and Ultra-nationalism \\ in 1946-1949 Essays
}

Brice FaUCONNIER CEJ, Inalco

\section{Introduction}

La critique de la modernisation du Japon est une pratique répandue parmi les intellectuels japonais au $\mathrm{xx}^{\mathrm{e}}$ siècle. Dans l'immédiat après-guerre, elle constitue généralement l'occasion de l'analyse des travers ou des défauts de la modernité japonaise. Les essais sur le fascisme et l'ultranationalisme des années 1946-1949 de Maruyama Masao s'inscrivent pleinement dans cette tendance. Ils entendent établir un bilan du processus de modernisation du Japon depuis l'ère Meiji (1868-1912) et de ses conséquences dans les années 1930 jusqu’à la guerre en Asie-Pacifique. 


\section{CIPANGO \\ 250 Cahiers d'études japonaises $n^{\circ} 23$}

Les titres des trois essais que nous nous proposons de présenter ici indiquent que la question globale de la modernisation, de ses effets catastrophiques sur la société japonaise et l'Asie de l'Est, est abordée sous l'angle des mentalités.

. « Logique et psychologie de l'ultranationalisme » (Chōkokkashugi no ronri to shinri 超国家主義の論理と心理), $1^{\text {re }}$ publication dans Sekai 世 界 (Monde), mai 1946.

. «Pensée et mouvements du fascisme japonais » (Nihon fashizumu no shisō to undō 日本ファシズムの思想と運動), série de cours donnés à l'université de Tōkyō, rassemblés dans Sonnō shisō to zettaishugi 尊王思 想と絶対主義 (La pensée de la souveraineté du tennō et l'absolutisme), juin 1947 ;

. «Formes de la mentalité des leaders militaires » (Gunkoku shihai-sha no seishin keitai軍国支配者の精神形態), $1^{\text {re }}$ publication dans Chōryū 潮 流 (Tendances du temps), mai $1949^{1}$.

Maruyama ne conteste pas que la modernisation matérielle lancée durant l'ère Meiji fût la condition sine qua non pour entrer en concurrence avec les puissances occidentales, ni qu'elle permît la militarisation de la société et la guerre. Il entend démontrer qu'elle n'est pas la cause principale de l'échec du développement japonais. Celle-ci est plutôt à trouver dans une modernisation des consciences abandonnée à mi-chemin, qui a compromis la formation d'une véritable démocratie, tout particulièrement dans l'absence d'un espace public d'expression entre dirigeants et dirigés. Les pratiques sociales s'en trouvent alors déséquilibrées et laissent place à plusieurs types de manifestations non démocratiques au sein du Japon ainsi que dans les relations entretenues pas le Japon avec l'extérieur².

1. Ces trois essais figurent dans le recueil classique Gendai seiji no shisō to kōdō, Maruyama, 2005 [1965], noté plus bas GSSK. Ces essais se trouvent aussi dans Maruyama, 1997, noté plus bas $M M S$, suivi du volume en chiffres romains et de la pagination.

2. Sur la mise en place déséquilibrée, durant l'ère Meiji, de la relation entre la sphère de l'État (notamment les droits publics et de police) et celle de l'individu (droits privés et 
Ces manifestations figurent dans les titres des trois essais, suivant les termes d'《 ultranationalisme », de « fascisme » et de « militaire » (c'est-à-dire de militarisme), mais les développements de chacun des essais recouvrent des phénomènes plus complexes.

L'ultranationalisme désigne de manière générale un discours patriotique centré sur la prééminence du tennō dans la politique nationale, par opposition à la politique menée par les élites « libérales » ou les militaires hauts gradés. Chez Maruyama, il s'exprime sous deux formes : d'une part le principe d'assistance au trône (taisei yokusan大政翼賛 ${ }^{3}$, c'est-à-dire au tennō ou à sa famille) auquel doivent se plier l'ensemble des sujets du tennō; d'autre part, les revendications populaires, allant jusqu'au terrorisme et aux tentatives de coups d'État, qui en

de la personne), voir « Logique et psychologie de l'ultranationalisme », GSSK, p. 13-16 $\& M M S$, III, p. 19-22.

3. Le terme yokusan 翼賛, traduit généralement par 《 assistance (au prince/au tennō) », se décompose ainsi : le premier caractère signifie d'abord « aile » mais aussi « aider », « protéger », « servir » (une personne), « offrir » (un présent, un service), « recevoir »; le second « rencontrer » (modestement), « aider », « servir » (idem), 《 féliciter ». Yokusan, associé au terme 《sujets» (shinmin 臣民) dans 《 soutien/ assistance de nos sujets » (shinmin yokusan 臣民翼賛), n'apparaît qu'à deux reprises dans la « déclaration du tennō » (kōmon 告文) préliminaire au texte de la Constitution du grand empire du Japon (Dai nippon teikoku kenpō大日本帝国憲法 ou Constitution de Meiji, promulguée le 11 février 1889). Source de la Constitution de Meiji : http://www.ndl.go.jp/constitution/etc/j02.html (lien vérifié le 09/12/2017 à 20h30). Le syntagme taisei yokusan 大政翼賛 (litt. 《assistance à la politique de l'État 》), traduit couramment par « assistance au trône », est devenu, avec celui d' « essence nationale » (kokutai 国体, cf. note 11), l'enjeu de débats et de luttes concernant les fonctions politique et symbolique du tennō dans les années 1930. Les crises à répétition et l'incapacité des gouvernements successifs à les régler aboutirent à une tentative de création d'une structure politique unique au sein de laquelle les partis politiques se sont auto-dissous le 12 octobre 1940 : l'Association du soutien au trône (Taisei yokusan-kai 大政翼賛 会), sous l'égide du noble Konoe Fumimaro. Elle fut renommée Association politique du soutien au trône (Yokusan seiji-kai 翼賛政治会) le 20 mai 1942. Le recyclage du terme confirme la place centrale de la redéfinition de la relation des sujets au tennō dans la politique de l'époque autant que sa fonction d'unification de la Nation. 


\section{CIPANGO}

252 Cahiers d'études japonaises $n^{\circ} 23$

appellent invariablement au tennō sans autre projet politique réel ${ }^{4}$. L'assistance au tennō constitue le ciment idéologique de la Nation, mais il peut servir, soit à justifier une position hégémonique et autoritaire dans la société (les dirigeants); soit d'argument pour contester cette hégémonie (une partie des dirigés les plus revendicatifs). En l'absence d'échanges démocratiques, l'espace public des interactions entre ces deux groupes se trouve, chez Maruyama, régulé par le principe d'assistance au tennō.

Le « fascisme à la japonaise » (nihonteki fashizumu 日本的ファシズ ム) est d'abord assimilé de manière générale à l'autoritarisme et au militarisme par Maruyama. Il désigne également l'ensemble de ces tendances contestataires hétéroclites et incohérentes qui se greffent sur l'ultranationalisme, dont les lignes oscillent entre archaïsme et modernité, par exemple : le familialisme est contredit par le travail des femmes lors de la mobilisation générale ; le repli communautaire et régional traditionnel s'oppose à la nécessité d'un État centralisé fort ; l'idée de panasiatisme fraternel est démentie par l'hégémonie militaire japonaise en Asie de l'Est, etc. Mais le fascisme, en tant que symptôme de la semi-modernisation de l'espace public, produit une classe sociale particulière qui contribue à la fois à reproduire l'autoritarisme au nom du tennō et le déformer en le reprenant à son propre compte. Maruyama l'appelle les « petits tennō » (shō tennō 小天皇) dont nous verrons en détail les caractéristiques 5 .

4. Les termes japonais utilisés par Maruyama pour désigner cette tendance sont : « sans logique 》 (hi ronri teki 非論理的) et 《 chimérique ( $k \bar{u} s \bar{o}$ teki 空想的). Voir 《Pensée et mouvements du fascisme japonais », GSSK, p. 49, 59, 63, 74 ou $75 \& M M S$, III, p. 281, 292, 296, 309. L'ultranationalisme et le fascisme à la japonaise ont pour points communs cette irrationalité et cette incohérence.

5. Voir «Pensée et mouvements du fascisme japonais ». Maruyama y utilise aussi le terme anglais “small masters” (sumōru masutaazu スモールマスターズ), GSSK, p. 70 \& MMS, III, p. 303. Le syntagme complet est « autorité de petits tennō » (shō tennō teki ken.i 小天皇的権威), ibid., GSSK, p. $66 \& M M S$, III, p. 299. Insistons ici sur le fait que Maruyama n’utilise pas le terme « légitimité » (seitōsei 正当性) pour qualifier la position de domination relative de ces « petits tennō », mais bien « autorité » (ken.i 権 威). Si cet usage lexical n'est pas explicité par Maruyama, il implique néanmoins une idée de captage, voire d'usurpation de la légitimité du mandat public officiel et reconnu par 
Si l'assistance au tennō, l'ultranationalisme et le fascisme ont des origines différentes, les deux premiers remontant à l'ère Meiji, le troisième s'imposant dans les années 1930, ils convergent tous dans une même dynamique liberticide et agressive subsumée sous le terme générique « fascisme ».

Nous nous attacherons d'abord à montrer, dans le présent travail, comment Maruyama explique cette convergence. Nous verrons dans la première partie qu'elle se comprend, dans les essais précités, selon trois niveaux d'analyse qui se répondent et s'entremêlent. D'abord un niveau historique avec la fonction du tennō en tant que symbole unique de cohésion de l'État. Ensuite sociologique, à travers la délimitation du rôle des véritables porteurs du fascisme que sont les « petits tennō ». Enfin psychanalytique, à partir de la détermination des causes profondes de la violence et de l'agression. Le point commun de cette triple approche est le déséquilibre des échanges entre dirigeants et dirigés évoqué juste avant. Ce déséquilibre est à la fois le produit de la semi-modernisation du Japon et la cause des débordements des années 1930.

Sur ce dernier point, Maruyama note que l'absence de véritable espace public d'expression, les contestations des dominés s'y manifestent non pas selon des débats ou des polémiques, mais sous la forme d'explosions de violences dont l'enjeu patriotique est invariablement la fonction du tennō dans la Nation et son instrumentalisation par les élites. Les déstabilisations et le terrorisme des ultranationalistes opèrent, dans ce cas, une pression sur les supérieurs hiérarchiques. La réponse des dirigeants japonais (politiques et hauts gradés de l'armée) n'est pourtant pas seulement autoritaire et répressive. Ils récupèrent, au nom de la légitimité du tennō, une partie des revendications nationalistes extrêmes venues des groupes ultras et les intègrent dans les politiques nationale et internationale sous diverses formes : exaltation de la Nation à travers le tennō, diplomatie agressive, invasion de pays étrangers. D'où le transfert de l'agressivité de l'intérieur vers l'extérieur. D'où aussi ce que Maruyama appelle, dans le troisième essai, le système d' « aresponsabilité » (mu sekinin 無責任) des leaders japonais, à savoir

la population dans un cadre d'élections démocratiques. Du moins, il dénonce la présence d'une incapacité à la pratiquer dûment dans l'espace public. 


\section{CIPANGO}

254 Cahiers d'études japonaises n²3

leur incapacité à assumer des décisions en accord avec la population et leur déni de responsabilité de la guerre après la défaite .

C'est l'ensemble de cette dynamique, qualifiée par Maruyama de « pathologique » pour les débordements du peuple et d'《 aresponsable » concernant les élites, que nous détaillerons dans la première partie.

La deuxième partie sera consacrée aux raisons de l'influence qu'eurent ces essais pour le moins complexes et techniques. On verra que la pérennité de la critique du fascisme (donc celle de la modernisation du Japon) doit plus à la simplicité de son découpage chronologique qu'à la sophistication de l'analyse de la dynamique exposée brièvement plus haut. L'originalité du traitement de questions autant historiques que politiques ou sociales tient aussi et surtout dans la capacité de Maruyama à réutiliser des lieux communs et des catégories pour en faire une théorie globale (ou holistique), en lien avec sa critique de la modernisation. Cette approche inclut enfin des éléments de l'actualité (le Procès de Tōkyō) pour les intégrer dans l'exposé de la logique de militaires, ce qui fait office de confirmation des analyses antérieures.

Nous finirons par un bref aperçu des difficultés et des problèmes non résolus par les trois essais. Le fait que les critiques adressées soient nombreuses indique d'abord que Maruyama reste incontournable. Les deux intellectuels que nous retenons le montrent.

Le premier point touche au statut de l'intellectuel par rapport aux « masses », décrites comme anonymes, violentes et irresponsables par Maruyama. Le long essai de Yoshimoto Takaaki 吉本隆明 (1924-2012) consacré à la représentation du peuple chez Maruyama nous montrera que ce point de vue est bien entendu difficile à maintenir sans faire de l'intellectuel la mesure de tout. Il nous fournira aussi des pistes pour le relativiser et en comprendre les origines.

Le second point concerne les difficultés posées par l'adaptabilité du terme « fascisme » au cas japonais à partir de deux exemples analysés par l'historien Tsutsui Kiyotada 筒井清忠 (1948) :

6. Ce point est détaillé dans l'ensemble de l'essai « Formes de la mentalité des leaders militaires ». Voir, en particulier, GSSK, p. 88-130 \& MMS, IV, p. 97-142. 
1. le « nanisme » (waishōsei 矮小性) du fascisme des militaires japonais avancé par Maruyama à l'occasion de la comparaison entre les procès de Nuremberg et de Tōkyō ${ }^{7}$;

2. l'absence supposée d'objectif politique précis chez les ultranationalistes et les « fascistes » japonais.

Nous constaterons que, confrontées à la série de contre-exemples proposés par Tsutsui, les catégories utilisées par Maruyama laissent nombre de questions en suspens, auxquelles seules des recherches historiques (ou empiriques, suivant la terminologie anglo-saxonne) peuvent répondre ${ }^{8}$.

\section{Les raisons et les manifestations d'une modernisation manquée}

L'enjeu principal des essais de 1946 à 1949 n'est donc pas la définition de l'ultranationalisme et du fascisme, mais plutôt de détailler les mécanismes profonds de trois phénomènes : les rapports dirigeants/dirigés, la diffusion de l'autoritarisme dans la société et l'agression. Dans ce cadre, chaque niveau présenté plus haut se trouve en interrelation pour former une construction théorique à la cohérence interne remarquable.

Le déséquilibre des relations dirigeants/dirigés met en lumière l'incurie des premiers (leur tendance à éviter toute responsabilité). L'autoritarisme n'est toutefois pas une simple oppression hiérarchique qui repose sur le principe d'assistance au tennō pour tous les sujets impériaux. Il est diffusé et déformé par ce que Maruyama appelle les « petits tennō » mentionnés en introduction. Il s'agit d'une partie des classes moyennes et des véritables porteurs du fascisme. Ils constituent, par leur autorité relative de dominés exerçant une autorité, les vecteurs de contestations et de violences qui remontent les chaînes hiérarchiques.

\section{Ibid.}

8. Maruyama utilise une analogie géométrique afin de montrer le mécanisme du principe d'assistance au tennō en tant que centre de toute valeur et de toute vertu. Faute de place, nous renvoyons à «Logique et psychologie de l'ultranationalisme », GSSK, p. 27-28 (éd. revue et augmentée) \& $M M S$, III, p. 35-36. 


\section{CIPANGO \\ 256 Cahiers d'études japonaises n²3}

Ces pressions sont l'origine des explosions de violence dirigées vers les dirigeants évoquées plus haut, qui les canalisent et les reprennent à leur compte au nom du principe patriotique que représente l'assistance au tennō. Cette chaîne logique explique la violence refoulée entre Japonais et sa libération brutale au sein de la société japonaise ainsi que vers l'extérieur. Le principe d'assistance au tennō fonctionne donc autant pour générer et justifier le sentiment patriotique que pour légitimer l'expansionnisme9. Ce point est en fin de compte confirmé par l'analyse psychanalytique des racines de la violence de Maruyama ${ }^{10}$.

Nous allons voir plus précisément les trois éléments centraux del'argumentation de Maruyama qui sous-tendent son interprétation de la modernisation manquée au Japon : l'assistance au tennō, les « petits tennō » et le mécanisme de la violence qui conditionne les relations dirigeants/dirigés.

\section{Le principe d'assistance au tennō : cobésion de l'État et logique de l'ultranationalisme à travers l'bistoire}

Maruyama souligne d'abord que les préalables indispensables à la définition de l'État de Droit - les droits naturels et le contrat d'association entre hommes -, ne furent pas discutés comme tels lors de la période dite de la Restauration de Meiji (de 1868 à 1889, année de la promulgation de la Constitution du grand empire du Japon). Ils furent remplacés par la définition de l'essence nationale (kokutai 国 体) et, nous l'avons vu, des fonctions du tenn ${ }^{-11}$. De ce fait, il n'y a pas d'espace public équilibré où des échanges de type démocratique peuvent se tenir.

\section{Ibid., GSSK, p. 28 \& $M M S$, III, p. 36.}

10. Cet aspect est développé dans « Logique et psychologie de l'ultranationalisme »et « Formes de la mentalité des leaders militaires ».

11. Le terme « essence nationale » (kokutai 国体), n'apparaît pas dans la Constitution de Meiji, mais est présent dans le Rescrit impérial sur l'éducation (Kyöiku ni kansuru chokugo 教育二関スル勅語, promulgué le 30 octobre 1890). Il fut l'objet de nombreuses publications dès les années 1870 , dont la plus citée est sans doute Kokutai shinron 国体新論 (Nouvelle interprétation de l'essence nationale), publiée en 1875 par Katō Hiroyuki 加藤弘之 (1836-1916). Incorporée dans les théories du Droit de l'État vers la fin des années 1910, la définition de cette «essence nationale» constitua le 
En lieu et place on assiste à une prééminence de l'État formulée de la manière suivante :

Le résultat du monopole, par la souveraineté de l'État, de l'autorité spirituelle et du pouvoir politique réunis, c'est que l'action de l'État porte le critère du contenu de la légitimité de son action en lui-même « en tant qu'essence nationale ». L'action intérieure et extérieure de l'État ne se plie, par conséquent, à aucun critère moral le dépassant.

国家主権が精神的権威と政治的権力を一元的に占有す る結果は、国家活動はその内容的正当性の規準を自らの うちに〈国体として〉持っており、従って国家の対内及 び対外活動はなんら国家を超えた一つの道義的規準には 服しないということになる12。

cœur des revendications ultranationalistes et des élites militaristes dans les années 1930. Elle fut l'occasion, à partir de février 1935, de la remise en cause de son interprétation 《 libérale » et d'attaques violentes contre le constitutionnaliste Minobe Tatsukichi 美 濃部達吉 (1873-1948), professeur de l'université de Tōkyō et membre de la chambre des Pairs. Cette affaire entraina sa radiation de la chambre, la censure de ses ouvrages, sa démission du poste universitaire ainsi que de deux « déclarations [du gouvernement] pour la clarification de l'essence nationale » (kokutai meichō seimei 国体明徵声明) en août et octobre 1935. Ces questions prirent une autre ampleur lors de la tentative de coup d'État du 26 février 1936 par une frange ultranationaliste de l'armée, qui fit appel à un retour et à une implication directe du tennō sur la scène politique (contre les politiques « libéraux » et l'état-major). Suite à son silence, l'armée rebelle, qui avait investi la Diète, se rendit. Des purges furent menées dans l'armée de Terre et le ministère de l'Éducation émit, en mars 1937, une publication de 150 pages intitulée Kokutai no hongi 国体の 本義 (Les points cardinaux de l'essence nationale), dont l'objectif était de répondre à l'ensemble des objections et des contestations concernant la définition de l'essence nationale, son rôle historique et ses relations avec le statut du tennō.

12. « Logique et psychologie de l'ultranationalisme », GSSK, p. 17 \& $M M S$, III, p. 23-24. Souligné par l'auteur. 


\section{CIPANGO}

258 Cahiers d'études japonaises n²3

L'ensemble des organes et des positions sociales des sujets impériaux tourne invariablement autour de cette essence nationale, la Constitution de Meiji (1889), le code de la maison impériale, les rescrits, dont le centre de toute légitimité a été accordé à la fonction du tennō. Les compétitions parmi les élites pour un accès direct à sa personne physique ainsi que pour la réforme de son rôle au sein de l'État prennent, lors des crises des années 1930 qui nous intéressent, non pas la forme d'une remise en cause de sa fonction, mais celle d'une « assistance au tennō » de tous ses sujets sans distinction de classe (hormis les nobles). Par conséquent, d'après Maruyama, c'est précisément suivant la proximité vis-à-vis du tennō que se constitue la norme de la hiérarchie sociale et non à partir d'un quelconque principe de légitimité du Droit ${ }^{13}$. Les mouvements ultranationalistes et fascistes violents des années 1930 n'échappent pas à cette logique. Ils remettaient juste en question, violemment et de manière désordonnée, aux yeux de Maruyama, l'instrumentalisation du tennō par les membres des cabinets successifs et les hauts gradés de l'armée.

Par contraste, l'assistance au tennō fonctionne chez ces élites comme une immense structure d'《 aresponsabilité » et non d'irresponsabilité, car ce dernier terme impliquerait une inviolabilité légale ou une déficience mentale que Maruyama n'accorde pas aux dirigeants. Auditionnés lors du procès de Tōkyō (1946-1948), leurs déclarations reviennent encore et toujours à l'assistance au tennō et à la défense de l'essence nationale, reprenant ainsi le discours officiel de la mobilisation générale et la légitimation de l'action militaire japonaise en Asie-Pacifique. Qualifiée, nous l'avons vu, de « nanisme » par Maruyama, cette expression particulière du fascisme japonais révèle précisément un autoritarisme liberticide caractéristique des pratiques politiques semi-modernisées ${ }^{14}$. L'image du mikoshi 輿, autel portatif sorti des sanctuaires en période sacrée, symbolise ce

13. Ibid., GSSK, p. 13 \& MMS, III, p 19-20.

14. Cette caractéristique est détaillée dans deux chapitres aux titres explicites de l'essai « Formes de la mentalité des leaders militaires » : «Nihon fashizumu no waishōsei »日本ファシズムの矮小性 (Le nanisme du fascisme japonais), $\mathrm{n}^{\circ} 1$ et 2, GSSK, respectivement p. 106-116, 116-128 \& $M M S$, IV, p. 116127, 127140. Elle apparaît aussi dans « Logique et psychologie de l'ultranationalisme », GSSK, p. 19 \& $M M S$, III, p. 26-27. 
mode de pensée ${ }^{15}$. Porté successivement par plusieurs personnes sans responsable prédéfini, il est ainsi censé montrer l'ambiguïté, voire une conscience incomplète de la responsabilité politique dans le Japon moderne. En ce sens, précise Maruyama, on ne peut assimiler le fascisme des dirigeants japonais au monisme du sujet politique du parti nazi ou à l'idée occidentale de dictature, puisqu'ils présupposent la prise de conscience de cette responsabilité par un sujet attitré ${ }^{16}$.

Issue des demi-mesures de la modernisation, l'assistance au tennō fonctionne donc autant comme un principe continu de l'État que comme une logique globale du patriotisme propre au Japon. Elle se manifeste plus particulièrement à travers l'attitude et le discours des dirigeants les plus proches de la personne du tennō car ce dernier est, selon les termes de Maruyama, « créateur de valeur » (kachi no sōzō-sha 価值の創造者) ${ }^{17}$. Dans ce cadre, le principe d'assistance au tennō s'articule en deux volets indissociables dans la hiérarchie sociale ainsi comprise par Maruyama. D'un côté, il permet aux élites de faire valoir, en tant que sujets impériaux, leur proximité vis-à-vis du tennō afin de légitimer leur propre autorité par rapport aux autres sujets en position inférieure ${ }^{18}$; de l'autre, il donne à une certaine partie de la population, appelée « petits tennō » et dominée par ces élites, la possibilité d'exercer, au nom de cette assistance au trône, une forme d'autorité sur leur entourage et les classes qui leur sont subordonnées. C'est ce mécanisme des interactions dirigeants/dirigés, en l'absence d'un espace public démocratisé digne de ce nom, que nous nous proposons d'exposer ici.

15. Cf. «Formes de la mentalité des leaders militaires », GSSK, p. 129 \& MMS, IV, p. 140-141.

16. Ces remarques sur l'« aresponsabilité » proviennent d'un autre texte postérieur aux premiers essais sur le fascisme et l'ultranationalisme : « Nihon shihaisō no sensō sekinin 》日本支配層の戦争責任 (Responsabilité de la guerre dans les classes dominantes japonaises), publié en 1956 et repris dans $M M S$, vol. annexe, p. 3-17 (1997). Certains points, notamment le rôle de la bourgeoisie et des classes moyennes, y sont considérablement résumés ou laissés de côté.

17. « Logique et psychologie de l'ultranationalisme », GSSK, p. $27 \& M M S$, III, p. 34.

18. Ibid., GSSK, p. 27-28 (éd. revue et augmentée) \& $M M S$, III, p. 35-36. 


\section{CIPANGO \\ 260 Cahiers d'études japonaises $n^{\circ} 23$}

\section{Les «petits tennō », vecteurs de l'autoritarisme et du fascisme dans un tissu social semi-modernisé}

Maruyama ne nie pas que certains groupes bien définis participent de la fascisation et de la militarisation du Japon. Parmi les nombreux acteurs identifiables durant les années 1930, et hormis l'armée, il cite d'abord les ultranationalistes terroristes civils, alliés à de nombreux militaires de grades intermédiaires déjà évoqués. Ensuite, l'influence du clientélisme des partis politiques « libéraux » dans cette fascisation, car il dessert la représentation démocratique et empêche par là même la création d'un espace public de discussion. Enfin, les organes d'État, principalement la bureaucratie et le grand capital, parce qu'ils jouent un rôle essentiel dans la mobilisation, la guerre et la restriction de l'expression publique ${ }^{19}$.

Maruyama détaille néanmoins deux types de population présents dans les « classes moyennes ${ }^{20}$ », répartis par activités professionnelles et, dans une moindre mesure, par occupation géographique, afin de déterminer les véritables porteurs du fascisme.

Le premier type regroupe des classes sociales comme : les propriétaires de petites usines, les contremaîtres d'usine de quartiers ; les artisans et entrepreneurs de construction ; les petits commerçants ; les maîtres charpentiers ; les petits propriétaires terriens ou fermiers indépendants ; les instituteurs, en particulier les enseignants du primaire et des collèges professionnels ; puis les petits fonctionnaires; les moines bouddhistes et les prêtres shintō.

第一には、たとえば、小工場主、町工場の親分、土建 請負業者、小売商店、大工棟梁、小地主、自作農上層、

19. Sur le rôle des partis politiques, voir « Pensée et mouvements du fascisme japonais », GSSK, p. $71 \& M M S$, III, p. 305. Sur le grand capital, ibid., GSSK, p. 30, $76 \& M M S$, III, p. 260, 310. Ibid., GSSK, p. 33-35 \& MMS, III, p. 263-267. Pour les considérations sur le rôle de la bureaucratie, ibid., GSSK, p. 31-40 \& MMS, III, p. 262-271.

20. «Pensée et mouvements du fascisme japonais », GSSK, p. 63-67 \& MMS, III, p. 296-301. Maruyama utilise les termes chükansō 中間層 et chükan kaikyū 中間階級. 
学校教員、特に小学校・青年学校教員、その他一般の下 級官吏、僧侶、神官とういうような社会層 ${ }^{21}$ 。

Parmi le second type, on trouve les employés de bureau en milieu urbain ; ceux qu'on nomme des personnes cultivées ou des journalistes; les intellectuels indépendants (professeurs ou avocats) ou les étudiants, bien que ces derniers offrent un cas particulièrement complexe et peuvent appartenir aux deux types. Je vous inclus provisoirement dans le second.

第二の種類としては都市におけるサラリーマン階級、 いわゆる文化人乃至ジャーナリスト、その他自由知識人 業者（教授とか弁護士とか）及び学生層——学生非常に 複雑でありまして第一と第二と両方に分かれますが、ま ず皆さん方は第二類型に入れるでしょう22。

C'est cependant une partie de la population politiquement moins influente, toujours intégrée dans la classe moyenne, qui constitue la cheville ouvrière du fascisme. Malgré sa longueur, la citation suivante montre bien les distinctions opérées par Maruyama afin d'isoler sa fonction toute particulière :

Par contraste [avec le second type, le premier] forme réellement la classe moyenne de la population et [il] est de loin plus pratique et actif que le premier. En outre, ses membres occupent une position de direction au sein de petits groupes régionaux et dans leur lieu de travail : magasin, mairie, groupes de travaux agricoles ${ }^{23}$ ou écoles. Ce sont ces personnes (employés de boutique, commis, travailleurs,

21. Ibid., GSSK, p. 63 \& MMS, III, p. 296-297.

22. Ibid., GSSK, p. 63-64 \& MMS, III, p. 297. À noter que la version anglaise, revue par l'auteur, ne comporte pas la dernière précision concernant les étudiants, voir Thought and Behaviour in Modern Japan, p. 57-58.

23. Ces groupes de travaux agricoles sont appelés nōgyō-kai 農業会. Ils furent créés comme structure légale de remplacement et d'encadrement des syndicats et des associations agricoles en 1943, donc tardifs dans l'encadrement de la population. 
artisans, terrassiers, employeurs, métayers, etc.) qui, sur la base de la composition patriarcale de la société japonaise, contrôlent effectivement les idées et la personnalité de leur « peuple », grâce à cette autorité de père face au petit fonctionnaire moyen. Du point de vue des appareils politiques et sociaux japonais dans leur ensemble, ils appartiennent clairement aux dominés et ne diffèrent guère de leurs « subordonnés » au regard du niveau peu élevé de leurs revenus et de leur mode vie. Pourtant, dans leur « petit univers », ils constituent sans aucun doute un type de dominant doté d'une autorité de petit tennō.

[第一のタイプ］に対して、[そのタイプ］は実質的に 国民の中間層を形成し、はるかに実践的行動的でありま す。しかも彼らはそれぞれ自身の属する仕事場、或は商 店、或は役場、農業会、学校等、地方的な小集団におい て指導的地位を占めている。日本の社会の家父長的な構 成によって、こういう人達こそは、そのグループのメン バー一一店員、番頭、労働者、職人、土方、傭人、小作 人等一般の下僚に対して家長的な権威をもって臨み、彼 ら本来の「大衆」の思想と人格とを統制している。こう いう人達は全体の日本の政治＝社会機構からいえば明ら かに被支配層に属している、生活程度もそんなに高くな く生活様式においては自分の「配下」と殆ど違わない。 にもかかわらず彼らの「小宇宙」においてはまぎれもな く、小天皇的権威をもった一固の支配者である ${ }^{24}$ 。

Par contraste avec l'autorité de ces « dominés-dominants » du second type, si l'on peut dire, la partie la plus éduquée et minoritaire de la classe moyenne est appelée « intelligentsia proprement dite 》 (honrai no interigencha 本来のイン テリゲンチヤ). Face à la montée du fascisme, elle adopta dans les années 1930

24. « Pensée et mouvements du fascisme japonais », GSSK, p. 65-66 \& MMS, III, p. 298-299. 
une attitude de 《résistance passive 》 (shōkyoku teki teikō 消極的抵抗), selon les termes de Maruyama ${ }^{25}$. À l'opposé, le caractère dynamique (c'est-à-dire revendicatif) des « petits tennō » et leur répartition dans la société japonaise en font la 《base sociale 》 (shakai teki jiban 社会的地盤) du fascisme ${ }^{26}$. Comment Maruyama explique-t-il à ce stade leurs interrelations apparemment simplifiées par sa schématisation ? Ces « petits tennō » remplissent en fait deux fonctions inséparables dans la mécanique du fascisme.

1. Dans un système fondé sur le principe d'assistance au tennō, la position de chaque individu se mesure à la valeur ultime que représente le symbole du tennō. Les rapports sociaux sont de type autoritaire. Les seuls à maintenir une forme d'indépendance, ce sont les intellectuels rétifs à l'égard du nationalisme, quelles que soient ses formes. Les « petits tennō » s'intègrent en revanche activement dans les rapports sociaux en tant que maillons hiérarchiques, en transmettant les consignes venues des supérieurs vers les inférieurs, en particulier si elles peuvent être énoncées comme «service/assistance au trône ».

2. Mais leur action ne se limite pas à une simple reproduction de l'autoritarisme ou des ordres de l'administration. Elle déforme aussi les consignes reçues et les diffuse grâce à leur position d'autorité relative, y compris à l'encontre des fonctionnaires chargés de transmettre lesdites consignes telles quelles. Ils constituent ainsi une sorte de parasitage des effets du centralisme étatique tout en se référant au tennō comme autorité de leurs contestations.

L'effet de cette répartition sociale de l'autorité est double pour Maruyama. Elle assure d'une part la cohésion patriotique de la population et sa participation active à la politique officielle toujours au nom du tennō. Mais de l'autre, elle court-

25.Ibid., GSSK, p. 64 \& MMS, III, p. 297. Maruyama se range explicitement dans le second groupe. À signaler que cette prise de position n'est plus présente dans la version anglaise.

26. Cf. citation note 24 . 


\section{CIPANGO \\ 264 Cahiers d'études japonaises n²3}

circuite la chaîne d'autorité en devenant le vecteur de contestations, notamment en temps de crise, lorsque les pressions provenant de la hiérarchie s'accentuent.

La violence a pour agents actifs ces classes moyennes subalternes sans réelle possibilité d'intervenir dans un espace public d'expression réduit ou quasi inexistant selon les périodes. Les raisons de leur implication dans le fascisme et le militarisme sont cependant plus profondes et leur échappent, car elles touchent aux racines psychanalytiques inséparables de l'état de semi-modernisation du Japon chez Maruyama.

\section{Les racines de la violence et la nature de l'oppression}

Résultats des déséquilibres issus du processus de modernisation, les modes de pensée des élites japonaises sont qualifiées à la fois d'aresponsables (en tant que simples sujets du tennō) et d'autoritaires (car usant de leur proximité vis-à-vis du tennō pour imposer leur politique). En face, les « petits tennō » ne sont pas entièrement passifs mais, sans leader unique comme chez les nazis. De quelle manière remplissent-ils la double fonction vue plus haut ? Mais comment gardentils une certaine marge de manœuvre par rapport aux supérieurs ? Maruyama répond à ces questions en deux étapes. En premier lieu la cohésion sociale est assurée par un mécanisme psychanalytique autoritaire dans la chaîne hiérarchique de la société :

À partir de l'absence de conscience de la liberté du sujet, sans dépendre pour limitation de ses propres actes de son âme et conscience, et si l'on se trouve conditionné par l'existence de son supérieur hiérarchique direct [...], en lieu et place de la notion de despotisme, se produit un phénomène qu'il est possible de nommer conservation de l'équilibre psychique par transfert du refoulement. Il s'agit d'un système qui préserve l'intégralité de son équilibre en transférant à tour de rôle le déploiement arbitraire, vers le bas, du sentiment d'oppression venu d'en haut.

$$
\text { さて又、こうした自由なる主体的意識が存せず各人が }
$$
行動の制約を自らの良心のうちに持たずして、より上級 
の者 [... $]$ の存在によって規定されていることからし て、独裁権念にかわって抑圧の移譲による精神的均衡の 保持とでもいうべき現象が発生する。上からの圧迫感を 下への恣意の発揮によって順次に移譲して行く事によっ て全体のバランスを維持されている体系である。27

Les « petits tennō » n'abusent donc pas sans raison de leur autorité. Ils font partie d'une chaîne d'oppression du haut vers le bas qui leur échappe et qui parcourt la société japonaise, chaîne sans laquelle l'organisation sociale ne pourrait se maintenir.

En second lieu, la capacité des « petits tennō » à réagir contre ce mécanisme éclaire sous un autre angle l'aresponsabilité et le nanisme des élites, à savoir leur inaptitude à organiser des échanges équilibrés entre dirigeants et dirigés.

Le « renversement de l'ordre subalterne/supérieur » est l'envers de la médaille du transfert du refoulement, son phénomène pathologique. Ce que j'appelle renversement de l'ordre subalterne/ supérieur, c'est, en fin de compte, l'explosion irrationnelle d'une force irresponsable et anonyme, qui ne survient que dans une société où les forces provenant d'en bas ne sont pas organisées publiquement. [... D]ans une société exclusivement gouvernée par une autorité venant du haut, le nanisme de dirigeants qui, par peur, sont attentifs aux tendances des subalternes ou des couches dominées, a pour conséquence une dépendance par essence envers les intentions des hors-la-loi ou des hommes de la rue irresponsables parmi ces classes inférieures. Dans un monde où le principe de transfert du refoulement existe, l'insatisfaction de la population qui se trouve au plus bas de la hiérarchie n'ayant plus d'espace où la transférer, se tourne inévitablement vers l'extérieur. Voilà pourquoi la population d'un pays non démocratique devient facilement captive du chauvinisme fanatique.

27. « Logique et psychologie de l'ultranationalisme », GSSK, p. 25 \& MMS, III, p. 32-33. Toutes les occurrences sont soulignées par l'auteur. 


\section{CIPANGO \\ 266 Cahiers d'études japonaises n²3}

「下攰上」は抑圧移譲の盾の半面であり、抑圧移譲 の病理現象である。下剋上とは畢竟匿名の無責任な力の 非合理的爆発であり、それは下からの力が公然と組織化 されない社会においてのみ起こる。[... からの権威によって統治されている社会は統治者が矮小 化した場合には、むしろ競々として部下の、あるいはそ の他被治層の動向に神経をつかい、下位者のうちの無法 者あるいは無責任な街頭人の意向に実質的にひきずられ る結果となるのである。抑圧移譲原理の行われている世 界ではヒエラルヒーの最下位に位置する民衆の不満はも はや委譲すべき場所がないから必然に外に向かれる。非 民主主義国の民衆が狂熱的な排外主義のとりこになり易 いゆえんでえる ${ }^{28}$ 。

Le mécanisme du refoulement et son explosion violente sont autant la source de l'évolution du fascisme japonais que de la violence entre Japonais, avant tout par manque d'espace public d'expression. L'agression vers l'étranger obéit au même fonctionnement ${ }^{29}$. L'assistance au tennō ne constitue pas pour autant un simple prétexte pour les dirigeants dans la théorie de Maruyama. Elle demeure l'ancrage patriotique de la Nation par excellence. Mais surtout, elle canalise l'agressivité des masses, récupérée par les dirigeants, phénomène des années 1930 appelé par Maruyama passage du « fascisme par le bas » (contestataire) au « fascisme par le haut » (institutionnalisé) $)^{30}$.

28. « Formes de la mentalité des leaders militaires », GSSK, p. 113-114 \& MMS, IV, p. 124-125. Toutes les occurrences sont soulignées par l'auteur.

29. « Logique et psychologie de l'ultranationalisme », GSSK, p. $20 \& M M S$, III, p. 27. Voir aussi les témoignages sur le massacre de Nankin et les prérogatives limitées des fonctionnaires comme contournement de la responsabilité dans « Formes de la mentalité des leaders militaires », GSSK, p. 118-120 \& MMS, IV, p. 129-132.

30. «Pensée et mouvements du fascisme japonais », GSSK, p. 31-40 \& MMS, III, p. 262-271. 
Si la logique de l'autoritarisme et de l'agression a pour origine un problème politique et social non résolu, c'est-à-dire avant tout l'échec de la création d'une relation équilibrée entre dirigeants et dirigés (ou un espace public d'échange démocratique), elle révèle ce qu'on pourrait appeler le bricolage institutionnel mis en place dans l'urgence durant les années 1880-1890. Bien que ce point ne soit pas explicité par Maruyama en tant que cause directe du fascisme, on peut dire que la place très réduite réservée à la majorité de la population dans le système constitutionnel et légal de l'ère Meiji est le facteur principal des débordements et des violences des années 1930. Les manifestations des colères populaires n'auraient en effet pas pris la forme particulière au Japon sans la fonction symbolique et politique du tennō, telle qu'elle a été définie par la constitution de l'Empire en 1889.

Les tensions économiques et politiques induites par l'environnement international, dont la Première Guerre mondiale accentue les effets, ont exacerbé les revendications populaires et les intérêts autour de la fonction d'unification de la nation du tennō. Les crises des années 1930 eurent pour effet de révéler plus encore les fragilités de ce bricolage. La « solution » des dirigeants revenait alors à une sorte de fuite en avant : la militarisation et la mobilisation de la société vers l'invasion en Asie de l'Est et la Guerre Asie-Pacifique ${ }^{31}$.

Les causes de ce processus de modernisation inachevé sont effectivement appréhendées globalement par Maruyama dans les essais de 1946 à 1949 : en tant qu'histoire politique, fonctionnement social et mode de pensée collectif. Cette approche holistique ne manqua pas d'impressionner à l'époque ${ }^{32}$. Ce n'est pourtant pas l'argument psychanalytique lui-même qui exerça le plus d'influence

31. « Formes de la mentalité des leaders militaires », GSSK, p. 111 \& $M M S$, IV, p. 121. Maruyama insiste sur le fait que les complots et les tentatives de déstabilisation furent acceptés ou confirmés après coup (le terme est tsui.nin suru 追認寸る) comme des « faits accomplis » (kisei jijitsu 既成事実), notamment par la hiérarchie militaire, afin d'influer par la suite sur la politique nationale.

32. C'est le cas, par exemple, de Tsurumi Shunsuke et de Kuno Osamu. Voir Kuno \& Tsurumi, 2003 [1956]. Les deux auteurs soulignent, en citant les travaux de Maruyama, le fait que le fascisme n'est pas uniquement un phénomène sous-tendu par des conditions matérielles, mais qu'il couvre aussi les questions de mode de pensée. 


\section{CIPANGO \\ 268 Cahiers d'études japonaises n²3}

dans la littérature critique sur la modernisation du Japon. On peut le comprendre pour deux raisons principales. Premièrement, les conclusions de Maruyama concernant les motifs des manifestations populaires, souvent considérées comme base potentielle de la démocratie en science politique, sont pour le moins négatives. Deuxièmement, le mécanisme psychanalytique de l'agression semble figer la nature même des échanges entre dirigeants et dirigés dans un cercle vicieux dont rien ne puisse les sortir, le Procès de Tōkyō servant de confirmation de ce mécanisme.

C'est plutôt la description de l'évolution du « fascisme » chez Maruyama, et tout particulièrement sa périodisation, qui séduisirent les commentateurs.

\section{L'influence des thèses de Maruyama}

Les mécanismes de la semi-modernisation du Japon exposés jusqu'ici représentent indéniablement le cœur des thèses de Maruyama. Pourtant, si l'influence d'un auteur se mesure aux éléments repris et commentés, ce ne sont pas les passages les plus utiles à la compréhension de son argumentation qui sont retenus, mais bien la périodisation du fascisme, sans doute parce qu'elle imprime une dynamique à la logique profonde du comportement des Japonais difficile à cerner de prime abord.

Nous nous limiterons à voir, dans cette section, comment la dimension historique s'articule avec les concepts vus jusqu'ici (assistance au tennō, refoulement, aresponsabilité, subversion de l'ordre dirigeants/subalternes), et de quelle façon le découpage chronologique s'intègre dans les trois essais. L'importance de la périodisation dans la critique du fascisme nous permettra dans un deuxième temps d'isoler quelques éléments propres, selon nous, à expliquer le succès et l'influence de ces trois essais.

\section{Une périodisation du fascisme au Japon}

Si, entre 1946 et 1949, l'originalité de Maruyama tient indéniablement dans son analyse des mécanismes psychanalytiques de l'agression, la périodisation des stades de développement $\mathrm{du}$ 《 fascisme à la japonaise » contribue pour une part essentielle à la cohérence de sa pensée, selon plusieurs niveaux qui, comme à son habitude, se répondent et s'entremêlent. 
La périodisation du fascisme fournit d'abord une série d'événements qui illustrent ses propos et surtout donnent sens à l'évolution même d'un « fascisme » issu de la convergence d'éléments hétéroclites. Elle permet, dans ce cadre, de montrer que les premières manifestations du «fascisme » telles que les nomme Maruyama, sont postérieures à l'ère Meiji (elles remontent à la fin de la Première Guerre mondiale) ${ }^{33}$. Ainsi, bien que les institutions mises en place à la fin du XIX ${ }^{\mathrm{e}}$ siècle soient indéniablement à l'origine de l'impossibilité des échanges démocratiques, elles ne portent pas en elle le «fascisme » tel qu'il prit forme par la suite.

Afin de maintenir la logique de sa critique globale de la modernisation du Japon, Maruyama se doit de situer le « fascisme » dans un processus international au sein duquel le Japon se trouve intégré : industrialisation lourde ; essor du « Grand Capital » ; expansionnisme en Asie de l'Est ; création de protectorats ; annexions de territoires, etc. Ces étapes ne sont de fait pas spécifiques au Japon. Parallèlement, les réponses japonaises à cette intégration apparaissent dans les particularités profondes qui ont été exposées dans la première partie de la présente étude. Mais, il s'agit sans doute du point le plus important car il renforce la cohérence de la critique de Maruyama, les éléments internationaux présents dans le découpage chronologique s'articulent avec deux des principes qui sous-tendent les relations sociales dans le Japon semi-modernisé :

1. le principe d'aresponsabilité des dirigeants constaté dans l'actualité du Procès de Tōkyō ;

2. celui de renversement de l'ordre supérieur/subalterne.

En effet, le passage du « fascisme par le bas » au « fascisme par le haut » évoqué plus haut, constitue non seulement une stratégie propre à la mentalité des dirigeants confrontés aux actions des subalternes : la récupération d'une partie de leurs revendications. Ce passage trouve aussi une signification proprement historique dans l'année 1936, comme transition entre les deux manifestations

33. « Pensée et mouvements du fascisme japonais », GSSK, p. 31-40 \& $M M S$, III, p. 262-271. 


\section{CIPANGO}

270 Cahiers d'études japonaises $n^{\circ} 23$

du fascisme. L'environnement mondial et les difficiles réponses du Japon ne font qu'un dans la linéarité chronologique.

Le résumé des stades du fascisme détaillés dans «Pensée et mouvements du fascisme japonais » (1947) ${ }^{34}$, montre ainsi le souci de Maruyama d'ancrer ses schémas logiques dans une suite d'événements, autrement dit de donner un cadre au vécu de nombreux Japonais ayant survécu dans l'immédiat après-guerre. Il définit trois stades dont l'évolution voit autant la montée d'un mouvement fasciste que sa convergence avec l'ultranationalisme.

. Stade 1. De 1918-1919 à septembre 1931 : période dite préparatoire, de la fin de la Première Guerre mondiale à l'« Incident de Mandchourie Manshū jihen 満州事変》(invasion de la Mandchourie par l'armée japonaise du Kantō, Kantō-gun 関東軍). Elle est caractérisée par des mouvements civils dits de droite 《uyoku/uha 》 (右翼/右派). Souvent de tendance anticapitaliste, ils sont sensibles aux questions de pauvreté, leurs revendications demandent plus d'intervention de l'État dans le secteur industriel ou d'aide pour les milieux ruraux.

- Stade 2. De 1931 au 26 février 1936 : période dite de maturité, de l'incident de Mandchourie à l' «Incident du 2 février 》 (ni ni roku jiken二 ・二六事 件, tentative de coup d'État par des officiers de l'armée de terre et environ 1500 soldats qui en appelèrent au tennō). Les mouvements civils se trouvent liés à des groupes militaires qui deviennent la véritable dynamique du fascisme et s'étendent lentement au cœur de la politique nationale par des actions terroristes, des déstabilisations des gouvernements successifs, des attaques contre les interprétations 《libérales 》 (jiyūshugi teki 自由主義 的) de la fonction du tennō. C'est la période des tentatives de coups d'État ou d'actions violentes du « fascisme radical » (kyūshin teki fashizumu 急 進的ファシズム), aux revendications hétéroclites et « chimériques » ( kūsōteki 空想的) jusqu'à sa version la plus organisée de février 1936.

- Stade 3. De février 1936 au 15 août 1945 : période dite d'achèvement (15 août 1945, déclaration radiodiffusée du tennō annonçant la fin des

34. Ibid. 
combats). Après les purges menées dans l'armée à la suite de février 1936, on assiste à la mise en place d'un fascisme par le haut caractérisé par une alliance instable de la partie non radicale de l'armée, de la bureaucratie, des dirigeants de l'exécutif d'une part, et du grand capital lié aux partis politiques de l'autre. Le fascisme aboutit alors à sa forme finale comme structure d'État.

La sélection des événements le montre, Maruyama ne dissocie pas la dynamique interne au Japon en réaction au milieu international et ses effets à l'étranger, ce qui correspond à la logique d'agression vue plus haut. La guerre totale en Chine (août 1937) et Pearl Harbor (décembre 1941), bien que non mentionnés, sont implicitement inclus dans le stade 3. Ceci ne signifie pas que ces deux événements ont une place secondaire, mais qu'ils ne purent voir le jour que lorsque la récupération complète du fascisme radical dans les structures de l'État permit la mobilisation générale et la guerre totale (années 1937-1938). Bien que non explicité, l'enchaînement des événements semble porter en lui une causalité confirmée par la logique des échanges entre Japonais vue en première partie.

À cet égard, le choix de ces événements est hautement significatif. Le 2 février 1936 est facile à identifier comme jalon de la phase dite de maturité, puisqu'il représente la tentative de coup d'État militaire la plus importante et la plus structurée des années 1930, contre la politique dite « libérale » et les abus du capitalisme, avec prise de la Diète par l'armée rebelle et un appel solennel au tennō. Le statut particulier attribué à septembre 1931, par exemple, peut sembler moins évident. En tant qu'invasion de la Mandchourie commandée par une partie de l'état-major de l'armée japonaise stationnée dans le Nord de la Chine ${ }^{35}$, septembre 1931 illustre néanmoins parfaitement le principe de renversement dirigeants/subalternes : les initiatives des officiers de grades intermédiaires auxquelles doivent répondre positivement, en tant que faits accomplis, les dirigeants (haut état-major et gouvernement). En ce sens, l'agression vers l'extérieur peut être interprétée comme une réaction de libération violente à une

35. On désigne cette partie de l'armée japonaise stationnée en Chine du Nord par le terme : «armée du Kantō » (kantō-gun 関東軍), en anglais Kwantung. 


\section{CIPANGO}

272 Cahiers d'études japonaises n²3

situation de refoulement dans les rapports hiérarchiques internes au Japon, sans que les causes directes soient identifiables à première vue.

Le découpage chronologique détaillé dans l'essai de 1947 (« Pensée et mouvements du fascisme japonais »), correspond donc aux priorités fixées par Maruyama dès son article de 1946 sur la logique de l'ultranationalisme (la fonction du refoulement dans l'équilibre social, l'assistance au tennō et l'aresponsabilité des dirigeants). Il n'y a en outre pas de contradiction avec les développements ultérieurs sur le renversement de l'ordre dirigeants/subalternes de l'article de 1949 («Formes de la mentalité des leaders militaires »). De ce fait, la périodisation du fascisme remplit, à notre nos sens, deux fonctions inséparables.

1. En mobilisant des éléments connus et vécus, elle représente certainement la partie la plus abordable de la théorie de Maruyama pour le lecteur.

2. En historicisant les facteurs psychologiques et les formes de mentalité plus profondes, elle demeure la partie plus exploitable pour le chercheur car, au sein de la logique interne de Maruyama de 1946 à 1949, elle fait à la fois office de facteur de cohésion et de pivot entre deux essais aux conclusions plus abstraites.

\section{Une théorie holistique}

Parallèlement à l'importance de cette périodisation dans la critique du fascisme chez Maruyama, il est possible d'identifier plusieurs facteurs qui contribuent à la longévité des trois essais considérés ici. Le premier facteur concerne le vécu des Japonais et le traitement de l'actualité ; le deuxième, la reprise de thèmes et de lieux communs des critiques du fascisme; le troisième, le positionnement de Maruyama comme alternative au marxisme.

1) Sans doute le succès et la pérennité de textes pour le moins complexes sont avant tout attribuables à l'effervescence et la soif de savoir de l'immédiat aprèsguerre au Japon. Les thèses de Maruyama répondaient à l'époque à un besoin de comprendre de manière globale « ce qui s'est passé » afin d'intégrer son vécu personnel dans une critique de la période vécue collectivement. L'essai de 1949, «Formes de la mentalité des leaders militaires », répond parfaitement à cette 
attente, car il exploite des éléments de l'actualité la plus directe, les dépositions des hauts gradés de l'armée lors du Procès de Tōkyō (1946-1948), pour les intégrer dans une réflexion sur les modes de pensée des dirigeants japonais en général : nanisme et aresponsabilité.

La simple constatation des dérobades des militaires japonais concernant leurs responsabilités durant la guerre, pour déroutante et scandaleuse qu'elle soit, nécessite un décryptage. Nous l'avons vu, elles se trouvent expliquées comme une véritable structure aux racines historiques (l'ère Meiji), mais aux formes contingentes (les années 1930 et 1940 jusqu'à la défaite). Une telle interprétation satisfait, selon nous, trois conditions minimales pour son succès :

1. elle offre une lisibilité à des comportements évasifs, voire suspectés de malhonnêteté, brouillés par le manque d'informations ou la désinformation des années de mobilisation générale ;

2. elle transforme le sentiment de rejet pur et simple des élites, patent depuis au moins la fin du premier conflit mondial au Japon, en une critique permettant d'interpréter le fonctionnement de ces élites donc, à terme, d'en changer ;

3. elle ne dédouane pourtant pas la population de ses travers, ce qui permet d'intégrer son propre voisinage parmi les zélateurs de la guerre après la défaite.

Le statut des intellectuels est, quant à lui, préservé. Il reste le garant d'une attitude critique et indépendante, si ce n'est d'une « résistance », dont les caractéristiques restent toutefois à préciser.

Grâce au traitement de l'actualité du jugement de la période de la guerre, le troisième essai de Maruyama se situe à la croisée de deux questions cruciales, à l'époque, pour qui veut comprendre le dérapage du cas japonais des années 1930 à la défaite : la comparaison avec le Procès de Nuremberg (1945-1946) et la dimension du témoignage. Le premier point est facilement intégré dans le schéma global de Maruyama puisque ce dernier est d'emblée comparatiste : le nanisme du fascisme japonais montre que, par contraste avec l'Allemagne nazie, et à cause de son état de semi-modernisation, la forme politique du Japon impérial donna un fascisme incomplet. Le second point est plus délicat car Maruyama n'a pas pour 
habitude de citer des témoignages. Pourtant, l'introduction d'extraits des minutes du Procès de Tōkyō dans l'essai de 1949 confirme d'emblée son diagnostic des manques du sujet politique japonais, tout en humanisant et naturalisant, en quelque sorte, ses schémas explicatifs. Les témoignages des militaires font non seulement figures, en tant qu'incarnations vivantes, de symptômes du nanisme et de l'aresponsabilité, ils confirment par la même occasion les analyses antérieures de Maruyama lors de leurs déclarations. De cette façon, Maruyama découvre la preuve de ses propres évaluations et intervient sur des sujets à première vue éloignés des questions d'histoire politique ou de psychanalyse collective de la violence. Grâce à son analyse, l'intellectuel demeure par la même occasion le révélateur des mécanismes des mentalités cachés sous les tergiversations des inculpés et le flou des motivations. D'où, certainement, la pérennité de ce terme de « nanisme » (waishōsei 矮小性) pour qualifier le fascisme japonais dès 1949.

2) Mais la durée et l'ampleur de l'influence des essais de 1946-1949 ne peuvent se trouver uniquement dans leur implication du moment. Que ce soit la périodisation ou les conclusions de 1949 sur le Procès de Tōkyō, l'influence de Maruyama sur quantité d'études postérieures tient aussi dans l'utilisation de lieux communs déjà présents dans les critiques du fascisme des années 1930. On peut par exemple citer : les différentes formes du militarisme ; le terrorisme, les assassinats et les déstabilisations des gouvernements successifs par les ultras; le rôle des grands conglomérats dans l'expansionnisme; le clientélisme des partis politiques ; les manœuvres des cliques de hauts fonctionnaires ; le rejet des valeurs « libérales » par la population, etc. Ces éléments, présents dans les essais de 1946 à 1949, parcourent les critiques de la militarisation du Japon entre 1931 et 1941 par de nombreux 《libéraux jiyūshugi-sha » (自由主義者), dont les plus connus sont sans doute Kawai Eijirō 河合栄治郎 (1891-1944), Hasegawa Nyozekan 長谷川如是閑 (1875-1969) et Kinoshita Hanji 木下半治 (1900-1989) ${ }^{36}$. Maruyama se positionne explicitement dans ce courant, particulièrement par ses

36. On trouve ces lieux communs dès le début des années 1930 parmi les intellectuels les plus critiques de la situation intérieure au Japon et de la politique étrangère des cabinets successifs. L'exercice de la critique du fascisme devient courant à l'époque, en premier lieu chez les marxistes, mais aussi chez certains « libéraux ». Pour ces derniers on peut citer : Hasegawa, 1932 ; Kawai, 1934 ; Kinoshita, 1936 \& 1939. Parmi les marxistes, 
thèses sur le rôle des intellectuels dans la résistance au fascisme et sa critique des militaires. S'il évolue sur un terrain déjà connu, il ne se contente pourtant pas de remettre au goût du jour des thèmes et des questions rebattus.

L'essentiel de l'originalité et de l'influence qu'eurent les essais sur le fascisme de Maruyama tient à cet égard en deux points : 1) la présentation, dans une théorie cohérente et holistique, de contenus et d'arguments préexistants, mais encore dispersés dans les études sur le fascisme japonais depuis le début des années 1930. 2) L'utilisation (limitée) de vocabulaire marxiste (capital, classes, peuple), déjà présent, par exemple, chez Hasegawa, mais justement pour se positionner contre les interprétations marxistes du fascisme des années 1930 et leur retour après la défaite ${ }^{37}$.

Le premier point contribue à renforcer le courant « libéral » d'après 1945 contre les thèses marxistes, précisément parce qu'il constitue une interprétation globale de la modernisation du Japon et de ses manques, grâce entre autres aux dimensions politique et psychanalytique du sujet japonais négligées par la plupart des marxistes. Si Maruyama se range explicitement dans ce courant issu de la période dite de la « démocratie de Taisho ${ }^{38}$ », il s'en démarque par la méthode

dont la bibliographie sur le fascisme et le «système impérial » (tennō-sei 天皇制) est pléthorique, citons juste un classique : Tosaka, 1935.

37. La dénonciation des abus du « grand capital » et de son rôle dansl' institutionnalisation du fascisme, déjà présente chez Hasegawa, réapparaît presqu'inchangée chez Maruyama. Voir «Pensée et mouvements du fascisme japonais », GSSK, p. 30, 76 \& MMS, III, p. 260, 310. Ibid., GSSK, p. 33-35 \& MMS, III, p. 263-267.

38. L'ère impériale Taishō est délimitée officiellement par les dates suivantes : 30 juillet 1912-25 décembre 1926. Le phénomène appelé « démocratie de Taishō » (Taishō demokurashī 大正デモクラシー) désigne une période moins précise, souvent circonscrite par deux conflits de grande ampleur chez les historiens d'aujourd'hui : la guerre russo-japonaise (1904-1905) et l'invasion de la Mandchourie par l'armée japonaise (1931). La « démocratie de Taishō » représente généralement une époque de libéralisation relative de la société japonaise avant la reprise en main autoritaire des années 1930 : l'émergence d'une culture populaire, l'urbanisation, le développement d'une presse indépendante et de mouvements contestataires dans un cadre institutionnel inchangé. Maruyama, dont le père était journaliste et proche de Hasegawa à cette époque, a hérité de cette culture d'intellectuel urbain. 
et la systématicité de sa critique du fascisme japonais. Autrement dit, il parvient à donner une cohérence à un phénomène apparemment incohérent ou jusque-là présenté par de simples études empiriques ou factuelles chez les non-marxistes.

Le second point montre que Maruyama, dès 1946-1949, se pose comme alternative possible aux théories marxistes de la modernisation, très en vogue à l'époque, en choisissant leur thème privilégié depuis la fin des années 1920 : le « fascisme ». Sa capacité à élaborer une critique globale le positionne comme rival privilégié des thèses marxistes sur les particularités japonaises au sein du développement historique mondial. Tout en reconnaissant, voire en empruntant, certains concepts marxistes (Grand Capital, dictature, masses), Maruyama développe une analyse totalement différente. Les défauts intrinsèques à la modernisation du Japon n'ont pas pour base les irrégularités du développement matériel : plutôt qu'économiques, nous l'avons vu, ces défauts dépendent d'un déséquilibre des relations politiques et de ses effets sur la psychologie des dirigeants et des masses. Sur ce point précis, la chronologie des stades de développement du « fascisme » qu'il propose représente clairement une interprétation concurrente des stades de développement de la base économique supposés applicables, avec ajustements, à de nombreuses situations de développement capitaliste ou précapitaliste ${ }^{39}$. En ce sens, la périodisation n'est pas uniquement un moyen de relier les mentalités, l'histoire et l'actualité en tant que maillon essentiel à la

39. À titre d'exemple, l'aspect du développement industriel n'est pas détaillé dans les trois essais, mais il n'échappe pas à Maruyama. Il considère l'importance du secteur des petites et moyennes entreprises de moins de cinq salariés comme un caractère de la 《 période féodale » (bōken jidai 封建時代), désignant sans doute par-là l'époque d'Edo, puisqu'il s'agit du type même de la «manufacture ». Le stade de développement manufacturier provoqua justement des débats houleux parmi les marxistes dans les années 1930. Couplé à la concentration capitaliste de l'industrie, il aurait été, pour Maruyama, un facteur décisif de blocage du développement démocratique à la fin du $\mathrm{XIX}^{\mathrm{e}}$ siècle, en partie lié à l'absence de véritable prolétariat. Cette idée emprunte autant aux thèses marxistes qu'elle entend s'en démarquer, parce que cette absence est précisément l'un des facteurs qui poussent à revoir la primauté des recherches sur les conditions matérielles (ou infrastructures) pour s'engager dans une approche centrée sur les mentalités. Sur la « période féodale », voir « Pensée et mouvements du fascisme japonais », GSSK, p. $82 \& M M S$, III, p. 316-318. 
cohérence argumentative de Maruyama. Sa dimension holistique parvient également à contester les modèles marxistes centrés sur le développement économique du Japon et donc à reconsidérer la signification même du « fascisme ».

C'est, à notre sens, ce positionnement autant académique que politique, qui a fait de Maruyama l'alternative « libérale » par excellence, par rapport au marxisme dans l'immédiat après-guerre au Japon, autant que le passage incontournable des recherches sur le Japon moderne, que ce soit pour le critiquer partiellement ou le réfuter entièrement.

\section{Limites et critiques :}

\section{les failles de l' « intellectuel libéral » et du comparatisme historique}

Le meilleur indicateur du statut d'intellectuel de Maruyama tient certainement dans le nombre d'études qui lui sont consacrées. Pourtant, tout comme son succès est massivement attribuable à la périodisation plus qu'à l'argument psychanalytique, la plupart des critiques ne portent guère sur la cohérence des trois essais de 1946-1949. On assiste plutôt à un dégradé allant du rejet pur et simple du terme «fascisme » à une analyse méticuleuse circonscrite à un point précis d'un des trois essais détaillés dans la première partie de la présente étude ${ }^{40}$. Cette tendance a eu pour effet de reléguer au second plan la description de la mécanique de l'agression, centrale dans la critique du fascisme chez Maruyama, au profit d'autres éléments plus facilement critiquables : encore et toujours le découpage chronologie, mais aussi le principe d'assistance au tennō, les notions de « masses » (taish $\bar{u}$ 大衆) de « classes moyennes 》 (chükankaiky $\bar{u}$ 中間階級) ou celle de dictature.

40. Le rejet, sans analyse critique, qui eut le plus d'influence est certainement : Itō, 1983a, p. 530. Parmi les nombreuses études sur Maruyama on peut citer en anglais : Kersten, 1996. Kersten fait une synthèse précieuse des idéologies et de la périodisation du fascisme de Maruyama et souligne, par-là même, certaines faiblesses de sa thèse concernant les masses. En japonais, citons juste : Gendai no shisō, 1994. Ce numéro contient de nombreux commentaires précieux pour comprendre la pensée de Maruyama sur le long terme, notamment le concept de « modernisme » (kindaishugi 近 代主義), qui sous-tend, sans être explicité, les essais de 1946-1949, y est interrogé. 
Néanmoins, parmi la pléthore de références aux thèses sur le fascisme de Maruyama, deux grands thèmes se démarquent parmi les commentateurs, car ils touchent aux aspects les plus délicats de son argumentation : le rapport des élites (intellectuels inclus) à la population et le comparatisme historique. Le premier point concerne ce que nous avons appelé le «statut préservé des intellectuels » (voir supra), en tant qu'unique garant d'une critique indépendante et la définition des véritables porteurs du fascisme japonais. Le second point est apparemment contingent, puisqu'il repose sur les dépositions des dirigeants japonais lors du Procès de Tōkyō. Cependant, puisqu'il repose précisément sur un comparatisme non explicité entre Allemagne et Japon, il dépend des thèses sur le degré supposé de modernisation atteint par le Japon et, par conséquent, de la nature du « fascisme à la japonaise ».

Deux intellectuels ont, à nos yeux, saisi ces difficultés avec le plus de lucidité : Yoshimoto Takaaki (ou Ryūmei) et Tsutsui Kiyotada. Non seulement, ils se sont intéressés à la logique de Maruyama présente dans les trois essais, mais ils ont tenté, assez précocement par rapport aux autres interprètes, d'élaborer une critique de ses présupposés.

Yoshimoto s'inscrit tout à fait dans le premier grand thème. Connu surtout pour ses poèmes et son activité de critique littéraire, il développe très tôt après la guerre, en tant qu'essayiste, des thèses sur les particularités de la modernisation du Japon, à travers des thèmes comme l'importance de la « culture populaire » (taishü bunka 大衆文化), le nationalisme et la fonction du «système-tennō » (tennō-sei 天皇制) ou le statut des intellectuels japonais. Autant à visée politique que théorique, son discours entend, de manière générale, se démarquer du marxisme et du libéralisme tels qu'ils furent adaptés au Japon. Ses essais sur Maruyama, publiés entre 1962-1963, interviennent sans aucun doute dans cette perspective de remise en question des non-dits des thèses libérales d'après-guerre sur le rôle des masses dans le fascisme ${ }^{41}$.

En tant qu'historien, Tsutsui réagit naturellement à un tout autre contexte. Son intérêt pour les essais de Maruyama a pour origine le rejet du terme

41. Cet intérêt de Yoshimoto pour les questions théoriques se poursuit avec un long essai sur Marx en 1964. Voir Yosнiмото, 1969a. 
« fascisme » parmi certains historiens vers la fin des années 1970. Stimulé par l'absence d'études d'histoire événementielle (ou empiriques) sur ce thème, Tsutsui commence sa réflexion par une lecture systématique des essais de Maruyama en 1976. Ses conclusions sur l'insuffisance de ses catégories l'incite à poursuivre une grande partie de ses recherches sur plusieurs niveaux : une sociologie des arguments des ultranationalistes des années 1930-1940 (particulièrement lors des minutes des procès des soldats et gradés intermédiaires de la tentative de coup d'État du 2 février 1936) ; une typologie des courants et dissensions internes au sein de l'armée ; une histoire des effets de la mobilisation générale sur la société et le monde politique de la même période. Son interprétation plus globale du processus ayant mené à la guerre prit forme dans les années $1980^{42}$. Elle constitue certainement une réponse argumentée à deux types de thèses courantes jusque-là :

1. celles qui se contentent de souligner l'inadaptabilité du terme « fascisme » dans le cas du Japon ;

2. celles qui uniformisent sous la catégorie « fascisme », quelles que soient la logique ou l'argumentation, la diversité des orientations politiques et des réactions populaires de l'époque.

L'ensemble des travaux de Tsutsui représentent certainement une remise au point en vue d'un comparatisme plus équilibré entre Japon et Allemagne.

Bien que les lectures de Yoshimoto et de Tsutsui mériteraient de longs développements, nous nous limiterons ici à exposer brièvement l'essentiel de leur argumentation à partir des deux grands thèmes évoqués plus haut. Chez Yoshimoto, on verra que le rapport élites/population se trouve analysé à partir de la nature tronquée de la vision des « masses » chez l'intellectuel Maruyama, vision péjorative essentiellement présente dans des textes sur son expérience de l'incorporation. Tsutsui nous intéressera, quant à lui, pour ses éclaircissements concernant deux points essentiels à la comparaison des cas allemand et japonais :

42. Voir la postface de Tsutsui, datée de 1984, ainsi que la liste des premières publications de chaque essai rassemblé dans le volume : Tsutsui, 2006 [1996], p. 409-414, 418. 


\section{CIPANGO \\ 280 Cahiers d'études japonaises $n^{\circ} 23$}

le parallèle entre les procès de Nuremberg et de Tōkyō, les simplifications induites par la catégorie « fascisme » pour décrire l'évolution des années 1935-1936.

\section{La position aveugle de l'intellectuel libéral chez Maruyama: le vécu et le «peuple » comme réalité extérieure à la théorie}

Un des problèmes soulevés par ce que nous avons appelé le « diagnostic » de Maruyama est précisément le statut préservé de l'Intellectuel évoqué rapidement supra. Intellectuel avec un grand «I » parce que, dans la classification de Maruyama, cette minorité désignée comme « hommes de culture » (bunkajin文 化人) ou 《intellectuels indépendants 》(jiyu chishikijin gyōsha 自由知識 人業者) se distingue des autres activités 《intellectuelles》 des petits tennō. La typologie des classes moyennes véhicules du fascisme montre que ces « intellectuels indépendants » représentent une frange extrêmement restreinte de la société japonaise, seule détentrice, à cause de son isolement du mécanisme socio-psychologique de la majorité, d'une forme de « résistance » au fascisme. « Homme de culture » et le reste de la population ne semblent alors guère pouvoir se rencontrer.

Yoshimoto Takaaki entend démontrer le caractère artificiel de cette distinction à partir de ce qu'il appelle l' « histoire quotidienne de la vie » (seikatsu-shi 生活 史) de Maruyama. Ses sources, encore éparses à l'époque, se trouvent dans des déclarations de Maruyama portant sur ses contacts avec la partie de la population la moins éduquée lors de son incorporation dans l'armée de Terre ${ }^{43}$. Ce choix n'est pas anodin. Il permet en premier lieu d'établir un lien entre la fonction des véritables porteurs du fascisme dans la théorie de Maruyama (la liste des « petits tennō ») et ses témoignages sur son propre vécu.

La défense du groupe auquel se rattache explicitement Maruyama, notamment la justification d'une « résistance passive » présente dans son analyse des véritables porteurs du « fascisme », tend bien sûr à éluder la complexité des changements de positions politiques et idéologiques du début des années 1930 à la défaite, sans parler des recompositions d'après-guerre. Yoshimoto avait déjà traité de cette

43. Үолнімото, 1969b, p. 16. 
question en 1958 dans « Essai sur le tenko ${ }^{-44}$ ». Son analyse de la notion de tenkō, en tant qu'abandon du credo révolutionnaire et des revirements idéologiques des marxistes, avait aussi été l'occasion d'une critique de l'intelligentsia japonaise en général ${ }^{45}$. Un des arguments central de Yoshimoto pour expliquer le retournement de certains leaders communistes dans les années 1930 tenait dans le fait qu' « ils n'avaient pas pu supporter leur isolement des masses » (taishü kara no koritsu ni taeenakatta 大衆からの孤立に耐え得なかった), entendu comme isolement intellectuel et psychologique des aspirations des masses ${ }^{46}$.

Pour explicites que fussent les cas de la majorité des marxistes, celui des « libéraux » était plus ambigu.

Les remarques de Yoshimoto sur ce point, dans ses essais consacrés spécialement à Maruyama, nous renseignent sur l'importance du trajet d'un intellectuel non révolutionnaire durant la période de crise des années de mobilisation générale (1938-1945). En reliant le vécu de l'incorporation et la théorisation des masses chez Maruyama, Yoshimoto confirme non seulement que l'expérience personnelle de l'incorporation sous-tend sa vision encore non explicitée de l'Intellectuel, il replace aussi la thèse de Maruyama sur les porteurs du fascisme au sein d'une interprétation plus large de la position des intellectuels « libéraux » de la guerre à l'après-guerre (Yoshimoto parle de riberaruリベラ ル). Dès 1958, Yoshimoto avait fait remarquer que la notion de tenkō, comme abandon explicite d'un engagement révolutionnaire, n'était pas adaptée à ces « libéraux », pour la simple raison que, leurs conditions de vie préservées, ils se contentaient en fin de compte de suivre les variations de la sociététe ${ }^{47}$. On retrouve l'argument du changement brutal de conditions ou de cadre de vie qu'est l'incorporation dans les essais de 1962. En ce sens, le vécu de Maruyama ne sert pas uniquement à montrer comment son aversion pour le peuple sert de base plus ou moins explicite à sa théorie. Il constitue, pour Yoshimoto, la condition même de sa position théorique et dénonce son appartenance au groupe des « libéraux »,

44. Yosнiмото, 1969 c.

45. Ibid., p. 17.

46. Ibid., p. 16.

47. Ibid., p. 19. 


\section{CIPANGO}

282 Cahiers d'études japonaises $n^{\circ} 23$

c'est-à-dire à une tendance plus large et stable de l'avant à l'après-guerre. En quelque sorte une continuité dans la bonne conscience et de la confiance en son propre statut. Et la caractéristique majeure de ce groupe par rapport au peuple tient dans une idée élitiste de la démocratie ${ }^{48}$. De ce fait, grâce et à cause de sa sophistication, Maruyama devient l'objet privilégié de Yoshimoto. Il représente le cas typique d'une autre forme moins explicite d'isolement des masses, formulée en 1962 comme la « dualité » (nijüsei二重性) desdits libéraux dans leur rapport à la période de la guerre ${ }^{49}$. La supposée « résistance passive » des véritables intellectuels avancée par Maruyama n'est, en fait, qu'une autre forme de rejet du peuple par les intellectuels libéraux (riberaru na chishikijin リベラルな知識 人). Par contraste avec les marxistes, la position qualifiée de «ni implications complètes dans la guerre, ni résistance directe à la guerre » (戦争そのものにの めりこみもしないが、それに抵抗することもしない) reste associée, pour Yoshimoto, à une interprétation étrangère à la réalité incarnée par le peuple ${ }^{50}$. Une réalité construite par le discours libéral bourgeois.

Le terme «peuple/masses », s'il n'est guère défini dans les essais sur Maruyama, remplit incontestablement la fonction de critère de comparaison par excellence. Quelles que soient ses réactions (ultranationalisme, révérence au tennō, militarisme, soumission ou désœuvrement après la défaite), « le peuple, pour Yoshimoto, vit par lui-même» (大衆はそれ自体として生きている) ${ }^{51}$. À cette évidence, base de l'existence et de la vitalité du Japon, Yoshimoto oppose la vision dominatrice et hiérarchique imposée par le haut avant et après-guerre, c'est-à-dire le système tennō utilisé par les militaires autant que la démocratie bourgeoise imposée par l'occupant américain en collaboration avec les dirigeants japonais $^{52}$. Si Maruyama qualifie son expérience auprès des soldats comme, tout

48. Үолнімото, 1969b, p. 19.

49. Ibid. p. 17-18.

50. Ibid., p. 17.

51. Ibid., p. 26.

52. Ibid., p. 26. 
au plus, d'《 insignifiante »(toriviaruトリヴィアル) $)^{53}$, c'est qu'une telle expérience, comparée aux dangers et au stress auxquels sont soumis les soldats, parfois contre leur volonté, est tout à fait représentative de la position de l'intellectuel citadin observant de loin les appelés (le terme utilisé par Yoshimoto est nagameru眺める $)^{54}$. On comprend alors mieux le terme « histoire de la vie » utilisé par Yoshimoto à propos de Maruyama. L'《 histoire de la vie » présentée par Maruyama n'est que le contre-point de sa représentation du peuple. Négligeant entièrement le mode de vie du peuple japonais (taishū no seikatsu yōshiki大衆の生 活様式), Maruyama ne l'évalue qu'au prisme de principes ou d'idées (rinen理念) qui proviennent de sa culture d'intellectuel citadin. Les concepts de démocratie, de liberté ou de dictature s'apparentent ainsi à des « représentations fictives » (kakō no imēji 仮構のイメージ) $)^{55}$.

En fin de compte, la seule particularité que Yoshimoto reconnaît à Maruyama par rapport aux autres «libéraux », réside dans le fait qu'il est hautement conscient des implications de sa vision du peuple. On le constate dans les relations entre ses propres expériences et sa théorisation des véritables porteurs du fascisme. Maruyama a donc intégré son vécu dans ses thèses en toute connaissance de cause $^{56}$. D'où, certainement, l'attention tout particulière apportée par Yoshimoto. Bien que radical, ce jugement sur la psychologie des élites intellectuelles de Yoshimoto touche effectivement le problème de ce qu'on pourrait appeler l'« Intellectuel-docteur », ou l'intellectuel auto-référent, seul à même d'évaluer correctement les symptômes du sujet qu'il s'est choisi.

Nombreuses sont les implications de cette critique, en particulier concernant la continuité des élites « libérales », au sens large, de l'avant à l'après-guerre, la reproduction d'un mode de pensée autoritaire de ces « libéraux » vis-à-vis des subalternes ou les changements de ce «peuple » aune de toute évaluation. Une étude séparée devrait être menée sur les réponses de Maruyama à ces questions.

53. Ibid., p. 22.

54. Ibid., p. 26-27.

55. Ibid., p. 26-28.

56. Ibid., p. 19. 


\section{Exemples et contre-exemples de l'aresponsabilité : les dangers du comparatisme dans l'histoire}

Yoshimoto aborde bien d'autres aspects de la méthode et du contenu des trois essais sur le fascisme de Maruyama mais, en tant qu'essayiste, son style est souvent polémique voire proche du pamphlet. Le trajet de chercheur de Tsutsui Kiyotada, entre histoire et sociologie, nous permet de comprendre d'une manière plus académique, et plus documentée, les problèmes non résolus par Maruyama.

Nous l'avons dit en introduction de cette partie, Tsutsui débuta ses recherches sous l'impulsion du rejet du terme « fascisme » chez des historiens japonais. Il est important de préciser que la remise en cause de la dénomination « fascisme » ne provenait pas, vers la fin des années 1970, de « révisionnistes historiques » qui réfutaient, par exemple, l'agression et les massacres de l'armée japonaise en Asie-Pacifique ${ }^{57}$. Il s'agissait, à l'époque, de professeurs occupant des postes universitaires, dont le plus connu est Itō Takashi, de l'université nationale de Tōkyōos8. L'insatisfaction liée aux abus et aux simplifications du terme « fascisme » dans l'analyse des années 1930-1940 au Japon a poussé Itō Takashi à rejeter, sans autre analyse, les thèses de Maruyama comme inutiles pour une enquête historique portant sur l'interaction des forces en présence dans les mondes politique et militaire de cette période. Pour légitime, et utile, que fût la réaction d'Itō, elle évolua vers la seconde moitié des années 1980 en une justification implicite de l'action militaire japonaise et révéla, par la même occasion, sa position nationalocentrée. Dans ce contexte, l'intérêt de Tsutsui Kiyotada est pour nous double.

57. Le syntagme « révisionnisme historique » a été utilisé dans le cas du Japon par Arnaud Nanta. Cf. Nanta, 2001, 2002a \& 2002b.

58. Cf. ITō, 1983a, p. 530. Itō se contente effectivement de remarquer l'inadaptabilité de la notion de fascisme, dont le meilleur représentant est Maruyama dans l'ouvrage précité. Il faut néanmoins préciser qu'il proposa dans plusieurs études des alternatives à l'utilisation du terme fascisme pour décrire l'évolution des années 1931-1945. En ce sens, il ne peut être assimilé à un simple « révisionniste historique », en dépit de son travail de « naturalisation » de la période de la guerre. Pour un schéma des forces en concurrence pour l'exercice politique entre 1936 et 1939 au Japon, voir Iтō, 1983b, p. 17. 
1. Contrairement à certains disciples d'Itō, qui firent un travail d'archives considérable des sources officielles tout en naturalisant le processus ayant mené à la guerre en Asie-Pacifique, Tsutsui maintint une position neutre concernant les implications politiques de l'abandon du terme « fascisme ${ }^{59}$.

2. Grâce à son intérêt pour les mouvements sociaux ultranationalistes et ses emprunts à la sociologie, il put échapper à une histoire des élites par le haut, dont la tendance est d'ignorer les effets des décisions politiques sur la population.

La relecture systématique des essais de Maruyama sur le fascisme constituait donc, pour Tsutsui, le préalable à une forme de bilan des catégories utilisées par les historiens japonais. Il s'agissait aussi de construire un cadre conceptuel général à même de répondre aux rejets ou aux critiques des historiens adressées à Maruyama. Ses réflexions l'ont mené à désigner le processus des années 1930-1940 comme une «normalisation » (heijunka平準化) de la société, lancée par le haut après l'échec du coup d'état de février 1936. Elle s'effectue principalement au moyen de purges au sein de l'armée, du lancement de la mobilisation générale et de l'invasion militaire de la Chine en $1937^{60}$. Cette « normalisation » est restée, dans certains domaines, incomplète : les dissensions dans l'armée sont multiples, certains groupes d'ultranationalistes demeurent et se réorganisent, les critiques du militarisme par certains politiques tentent de contrecarrer le vote du budget de l'armée, les contestations populaires ne sont pas inexistantes, etc. Ces thèmes, essentiels à une meilleure compréhension de cette période, ont été largement

59. Le travail d'archives considérable des disciples d'Itō comporte la même tendance à présenter la guerre comme une pratique légale et normale car basée sur des procédures dûment votées. Le sérieux des recherches s'accompagne par là même d'une relativisation des responsabilités et d'une édulcoration de la critique du processus ayant mené à l'invasion de la Chine et à l'attaque de Pearl Harbor. Parmi les plus brillants de ces disciples, il faut citer : Moriyama, 1998 ; Furukawa, 2005.

60. «Dai ni shō Senkanki Nihon ni okeru heijunka purosesu »第二章 戦間期日 本における平準化プロセス (Chapitre II. Le processus de normalisation au Japon durant la période de guerre); Tsutsui, 2006 [1996], p. 65-114. 
examinés par Tsutsui jusqu'à nos jours ${ }^{61}$. Ils touchent directement au problème central de l'évolution de la société japonaise des années 1930 à la défaite et la comparaison avec le nazisme ou le fascisme italien.

Nous nous limiterons ici aux deux questions évoquées plus haut concernant la critique les essais de Maruyama. Elles apparaissent en filigranes chez Yoshimoto et d'autres commentateurs, mais Tsutsui nous semble les avoir résumées avec le plus de précision : le comparatisme historique à travers les procès de Nuremberg et de Tōkyō ; les contre-exemples qui révèlent les simplifications de la catégorie « fasciste ».

1) Le parallèle entre les deux grands procès de l'après-guerre concerne principalement le troisième essai : «Formes de la mentalité des leaders militaires ». Il comporte certains dangers bien isolés par Tsutsui. Les dérobades des dirigeants, principalement militaires, lors des audiences à Tōkyō, semblent avérer le « nanisme » du fascisme japonais et, par là même, confirmer l'ensemble du système d'aresponsabilité qui permit de formuler ses propres responsabilités pour de l'assistance au tennō. Cette tendance est inconsciente au Japon selon Maruyama, par contraste avec l'attitude d'Hermann Wilhelm Göring, qu'il prend pour exemple ${ }^{62}$. La représentativité de Göring n'est pas à remettre en cause et elle sert, dans la logique de Maruyama, à marquer les différences entre nazis et militaires japonais tout en confirmant l'absence de dictature dans le Japon impérial. C'est toutefois négliger d'autres dépositions, Tsutsui le souligne, comme celle de Ribbentrop ou de Wilhelm Keitel ${ }^{63}$, identiques aux Japonais

61. On le constate dans son étude sur le personnage de Konoe Fumimaro 近衛文麿 (1891-1945), noble, chef de trois cabinets entre 1937 et 1941, promoteur du mouvement pour un ordre nouveau et leader de l'Association du soutien au trône en 1940, il se suicida après avoir été classé criminel de guerre classe A par les forces d'occupation. Tsutsui, 2009.

62. Sur Göring, voir «Logique et mentalité de l'ultranationalisme », GSSK, p. 20 \& $M M S$, III, p. 28. Concernant les comparaisons entre Allemagne et Japon, voir « Pensée et mouvements du fascisme japonais », GSSK, p. 57 \& $M M S$, III, p. 289-290.

63. Nom complet : Wilhelm Bodewin Johann Gustav Keitel (1882-1946). Chef du grand état-major de la Wehrmacht, il s'opposa à plusieurs reprises à Hitler (notamment concernant l'invasion de la Pologne), mais parapha tous les ordres jusqu'à la défaite. 
dans leur rejet de toute responsabilité personnelle, dont l'objectif était avant tout d'éviter la peine de mort. À cet égard, Tsutsui remarque que le fait d'éluder sa propre responsabilité, quand il ne revient pas simplement à incriminer une personne décédée (Hitler), passe souvent par l'argument de ce que nous pourrions appeler la «délimitation d'une mission », que ce soit au service de l'État, du führer, du tennō, de la chaîne de commandement de l'armée ou d'une fonction administrative ${ }^{64}$.

Il ne s'agit plus, à ce stade, de la comparaison des différences entre régimes, mais de la validité des témoignages évoqués plus haut, ainsi que des stratégies de défense mise en place en face d'un tribunal. Tsutsui fait remarquer que ces stratégies étant, à l'exception de Göring, entièrement communes au Japon et en Allemagne, en conséquence, le principe d'aresponsabilité et le « nanisme » qui l'illustre dans la théorie de Maruyama, sont à revoir ${ }^{65}$.

Outre les « représentations fictives » dénoncées par Yoshimoto, cette propension à vouloir faire plier des faits avérés pour les intégrer dans une théorie est souvent due à la pratique d'une sorte d'histoire immédiate et à l'influence de l'actualité sur la sélection des exemples illustrant la théorie.

2) Le second point touche une question plus complexe, à savoir l'utilisation du terme « fascisme ». Il est clair que Maruyama n'a pas pour programme de redéfinir le concept de fascisme. Comme nous l'avons vu, il utilise un terme galvaudé et riche en lieux communs, mais en les réorganisant dans une interprétation holistique et cohérente. Plusieurs questions ne sont pourtant guère explicitées. D'abord, il n'y a pas de distinction claire entre « fascisme » et « ultranationalisme » chez

Condamné à mort par le tribunal de Nuremberg, il avait plaidé non coupable, puis avança l'argument d'une obéissance sans limite après avoir reconnu ses erreurs. Son cas est, pour Tsutsui, bien plus représentatif que celui de Göring.

64. « Dai isshō "Nihon fashizumu"-ron no saikōsatsu - Maruyama-riron e no ichi hihan 2. “Gunkoku shihaisha no seishin keitai” 》第一章「日本ファシズム」論 の再考察一丸山理論への一批判 2 「軍国支配者の精神形態」 (Chapitre I. Reconsidérer les interprétations du « Fascisme japonais » : une critique de la théorie de Maruyama 2. «Formes de la mentalité des leaders militaires »); Tsutsui, 2006 [1996], p. 19-20.

65. Ibid., p. 22-24. 
le Maruyama de 1946-1949. Si l'on se réfère à sa périodisation vue plus haut, le fascisme est postérieur à l'ultranationalisme, dans la mesure où le stade 2 , dit de maturité, commence en 1931. La logique de Maruyama semble confirmer cette différence, puisque le principe d'assistance au tennō précède et sert de base aux dérives terroristes des années 1930.

Tsutsui le souligne clairement : plusieurs problèmes non résolus demeurent dans l'interprétation de Maruyama « historien » et non dans la cohérence de sa théorie. Le premier point illustrant la méthode de l'《 historien » Maruyama concerne la convergence supposée entre ultranationalismes. Tsutsui souligne à raison que le fascisme ne repose pas sur une analyse du discours des acteurs des années 1930. Le caractère prétendument « chimérique » des écrits et des déclarations des « fascistes 》 est infirmé par les dépositions des « terroristes 》 lors de leurs procès en 1936 ainsi que leurs notes de prison ${ }^{66}$. Le travail de reconstitution des «faits » historiques de Tsutsui montre la constance des critiques du capitalisme et des dirigeants (hauts gradés compris) parmi les prévenus jugés pour actes terroristes (militaires et civils compris). L'appel au tennō (ou dans certains cas à la famille impériale) n'est, dans ce cas précis, pas simplement le fait de quelques illuminés ou un prétexte pour éviter une quelconque responsabilité, mais l'argument clé pour invoquer la mise en place d'une autre organisation politique au sein de laquelle le contact direct avec le symbole de la Nation serait rétabli ${ }^{67}$. Ce discours, particulièrement bien présenté par Tsutsui, est le révélateur d'une crise de représentation politique. Mais il dénonce aussi les crises de subsistance, notamment les disettes et l'indigence qui sévissaient à l'époque dans les régions rurales du Nord (la région du Tōhoku). Tsutsui constate d'ailleurs que, d'après

66. Certains éléments sur le discours des ultranationalistes apparaissent dans les rapports des autorités et leurs propres programmes. Sur ce point, voir ibid., « 4 "Nihon fashizumu" no undō keitai »4「日本ファシズム」の運動形態 (Les formes de mouvement du « fascisme japonais »), p. 343. Les dépositions et les notes ou carnets de prison sont détaillés dans ibid., « Dai go shō Nihongata kūdetā no kōsō to gakai - Ni ni roku jiken kenkyū I » 第五章 日本型クーデターの構想と瓦解一二・二六事件研究 I (Chapitre 5. Conception et effritement des coups d'État de type japonais : étude sur l'Affaire du 26 février 1936 I), p. 255-300.

67. Ibid., p. 256-263. 
l'examen des minutes des procès liés à la tentative de février 1936, l'écrasante majorité des prévenus provenait de cette zone du Japon ${ }^{68}$.

Cet aspect social du problème politique est en lien avec une seconde difficulté posée par l'utilisation du terme «fascisme » chez Maruyama : le passage du « fascisme par le bas » (radical) au « fascisme par le haut » (institutionnalisé). Si l'on considère que l'impuissance des gouvernements successifs à régler la crise économique des années 1930, aggravée par la série de tentatives de coup d'État, entraîne une reprise en main par l'armée et une fuite en avant vers la mobilisation générale, ce passage semble effectivement évident. Mais, en regroupant sous la catégorie « fasciste » l'avant et l'après 1936, Tsustui le remarque justement, il ne dit rien des nombreux aspects politiques et sociaux de ladite période : que dire de la continuité légale, constitutionnelle, et le vote de mandats électifs d'avant et d'après 1936 ? Comment identifier les modes de décision des dirigeants et les interactions des groupes en présence au sommet de l'État ? Comment qualifier les différences du régime politique japonais avant et après 1936, s'il reste dominé idéologiquement par l'assistance au tennō, mais devenu « fasciste » après $1931^{69}$ ?

Ces questions ont précisément poussé Tsutsui, et les disciples d'Itō Takashi, à regarder de plus près les concurrences et les contestations au sein de l'armée, les réseaux de hauts fonctionnaires, le fonctionnement des partis politiques ou les compétitions autour et au sein du palais impérial. Autant de recherches spécialisées qu'il faudrait présenter au public français mais qui doivent, dans un sens, leurs motifs à l'insatisfaction créée par Maruyama lui-même.

\section{Conclusion : que faire des essais des années 1946-1949?}

Pourquoi encore appeler « fasciste » la période dont les interprétations souffrent d'autant de questions non résolues ? Sans doute parce qu'aucun autre terme n'eut à la fois une connotation aussi péjorative et une polysémie équivalente. Mais il ne s'agit pas uniquement d'une question de sémantique et de déictique. Nous avons

68. Ibid., p. 257-262.

69. Tsutsui offre des réponses très documentées qu'il est impossible de développer ici. Nous invitons à se reporter aux chapitres 2, $3 \& 4$ de Tsutsui, 2006 [1996]. 


\section{CIPANGO \\ 290 Cahiers d'études japonaises n²3}

à plusieurs reprises insisté sur ce point, les thèses de 1946-1949 de Maruyama ont gardé une partie de leur intérêt grâce à la cohérence de leur complexité théorique, alors même que c'est la périodisation tout à fait problématique qui eut le plus de succès. Cependant, ce qui n'apparaît guère dans les essais de 1946-1949, c'est que l'usage du terme «fascisme » chez Maruyama, comme pour de nombreux chercheurs de sa génération (y compris les intellectuels classés « marxistes »), repose sur la nécessité d'un stade «fasciste » dans le développement de certaines nations au sein du processus de modernisation supposé comme tardif dans l'histoire mondiale, tels le Japon, l'Italie, l'Allemagne. Cette représentation de l'Histoire a été justement critiquée comme une aporie de l'idée de progrès chez Maruyama $^{70}$.

C'est précisément contre cette tendance que Yoshimoto et Tsutsui se sont insurgés. Le premier, en classant Maruyama parmi les « intellectuels libéraux citadins », fait référence à une forme de continuité dans la représentation hiérarchique que la «bourgeoisie » a du peuple depuis les années de la « démocratie de Taishō » (1910-1925) jusqu'après la guerre. Éclairée ou non, cette bourgeoisie entend maintenir son rôle d'éducateur. Le « progrès » qui doit passer par cette mission se trouverait plutôt assimilé à une répétition des mêmes schémas de domination pour Yoshimoto. Tsutsui, en insistant sur la cohérence du discours des ultranationalistes issus du peuple dans les années 1930, souligne l'existence d'une conscience politique centrée non pas sur l'assistance au trône avancée par les élites, mais sur un appel à une intervention directe du tennō dans les affaires politiques. Tsutsui montre que, si progrès il y a à l'époque, il a déjà atteint le discours des couches les moins éduquées de la population, quelle que soit leur réelle compréhension des questions politiques ou internationales.

À cet égard, si l'assistance au trône, c'est-à-dire au tennō, fonctionne comme le ciment du patriotisme dans les thèses de Maruyama, ce mécanisme repose sur l'absence de la personne de Hirohito, vers lequel tout converge pourtant ${ }^{71}$. La

70. YAMAGUCHI, 2000.

71. Ce point sera corrigé en partie en 1956 dans «Sensō sekinin no mōten » 戦争責任

の盲点 (Les points aveugles des responsabilités de la guerre), dans MARUYAMA, 1976, p. 596-602. 
logique même de l'assistance n'a pas besoin de l'individu. Le rejet quasi complet des responsabilités de la guerre sur les militaires, admis majoritairement à l'époque du procès de Tōkyō, permettait de maintenir la cohérence de la critique du fascisme à tous les niveaux pour les intellectuels japonais. Concernant Maruyama, le passage du « fascisme par le bas » au « fascisme par le haut », central dans sa périodisation, dépendait effectivement du rôle central joué par l'armée dans le processus d'institutionnalisation du fascisme. Cette logique était en accord presque total avec le Procès de Tōkyō, duquel Hirohito avait été écarté après une période d'hésitation parmi les autorités d'occupation.

Ces questions ne semblent guère avoir motivé Maruyama à répondre point par point à ces critiques, malgré sa longévité remarquable (né en 1914, il décède en 1996). Ce point a été souligné par Rikki Kersten et semble confirmer une nouvelle fois le statut de l'Intellectuel à partir duquel Maruyama a poursuivi ses recherches ${ }^{72}$.

\section{Abréviations}

GSSK : MaruYama Masao, Gendai seiji no shisō to kōdō 現代政治の思想と行

動 (Pensée et comportements dans la politique contemporaine).

MMS : Maruyama Masao shū 丸山真男集 (CEuvres de Maruyama Masao).

\section{Liste des références citées}

FURUKAWA Takahisa 古川隆久, 2005, Shōwa senchūki no gikai to gyōsei 昭和戦 中期の議会と行政 [Parlement et exécutif pendant la guerre de l'ère Shōwa], Yoshikawa kōbun-kan 吉川弘文館, Tōkyō, 300 p.

72. Kersten, 1996, p. 162. 


\section{CIPANGO}

292 Cahiers d'études japonaises $n^{\circ} 23$

Gendai no shisō tokushū Maruyama masao «seiji no kōzō», 1994, 現代の思 想 特集丸山眞男「政事の構造」 [La pensée d'aujourd'hui, $n^{\circ}$ spécial « Maruyama Masao "la structure des affaires politiques" »], vol. 22, Seidosha 青土社, Tōkyō, 56-238 p.

Hasegawa Nyozekan長谷川如是閑, 1932, Nihon fashizumu hiban 日本フ アシズム批判 [Critique du fascisme japonais], Ōbatake shoten大畑書店, Tōkyō, $411 \mathrm{p}$.

ITō Takashi 伊藤隆, 1983a, Shōwaki no seiji 昭和期の政治 [La politique durant l'ère Shōwa], Yamakawa shuppansha 山川出版社, Tōkyō, 400 p.

ITō Takashi 伊藤隆, 1983b, Konoe shintaisei, taisei yokusan-kai e no michi 近衛 新体制・大政翼賛会への道 [Le nouveau régime de Konoe, le chemin vers l'Association de soutien au trône], Chūō shinsho 中央新書, Tōkyō, 234 p.

KAWAI Eijirō 河合栄治郎, 1934, Fashizumu hihan ファシズム批判 [Critique du fascisme], Nihon hyōronsha日本評論社, Tōkyō, 524 p.

Kersten Rikki, 1996, Democracy in Postwar Japan, Maruyama Masao and the search for autonomy, Routledge, London \& New York, p. 137-163.

KInOSHIta Hanji 木下半治, 1936, Nihon fashizumu 日本ファシズム [Le fascisme japonais], Naukashaナウカ社, Tōkyō, 267 p.

Kinoshita Hanji 木下半治, 1939, Nihon kokkashugi undō-shi 日本国家主義 運動史 [Histoire des mouvements nationalistes japonais], Keiō shobō 慶應 書房, Tōkyō, 556 p.

Kuno Osamu 久野収 \& Tsurumi Shunsuke 鶴見俊輔, 1956, Gendai Nihon no shiso- Sono itsutsu no uzu 現代日本の思想一その五つの渦 [La pensée du Japon contemporain : cinq de ses maelströms], Iwanami shinsho 岩波新書, Tōkyō, p. 126-128. 
MARUYAma Masao 丸山真男, 1946, «Chōkokkashugi no ronri to shinri » in 超国家主義の論理と心理 [Logique et psychologie de l'ultranationalisme], $1^{\text {re }}$ publication dans Sekai 世界 [Monde].

Maruyama Masao 丸山真男, 1947, « Nihon fashizumu no shisō to undo » in 日本ファシズムの思想と運動 [Pensée et mouvements du fascisme japonais], série de cours donnés à l'université de Tōkyō, rassemblés dans Sonnō shisō to zettaishugi 尊王思想と絶対主義 [La pensée de la souveraineté du tennō et l'absolutisme].

MARUYAma Masao 丸山真男, 1949, 《Gunkoku shihai-sha no seishin keitai » in 軍国支配者の精神形態 [Formes de la mentalité des leaders militaires], $1^{\mathrm{re}}$ publication dans Chōryū 潮流 [Tendances du temps].

Maruyama Masao 丸山真男 et al., 1963, Thought and Behaviour in Modern Japan, transl. Morris Ivan, Oxford University Press, Tōkyō, Oxford \& New York, 407 p.

Maruyama Masao 丸山真男, 1976, Senchū to sengo no aida 1936-1957 戦中と 戦争の間 1936-1957 [Entre la guerre et l'après-guerre 1936-1957], Misuzu shobōみすず書房, Tōkyō, 635 p.

Maruyama Masao 丸山真男, 1997, Maruyama Masao shū 丸山真男集 [OEuvres de Maruyama Masao], vol. 3, 4, 5 \& annexe, Iwanami shoten 岩波 書店, Tōkyō.

Maruyama Masao 丸山真男, 2005 [1965], Gendai seiji no shisō to kōdō 現代政治の思想と行動 [Pensée et comportements dans la politique contemporaine], Miraisha 未来社, Tōkyō, 585 p.

Moriyama Atsushi 森山優, 1998, Nichibei kaisen no seiji katei 日米開戦の政 治過程 [Le processus de décision politique vers la guerre nippo-américaine], Yoshikawa kōbun-kan 吉川弘文館, Tōkyō, 272 p. 


\section{CIPANGO}

294 Cahiers d'études japonaises $n^{\circ} 23$

Nanta Arnaud, 2001, « L'actualité du révisionnisme historique au Japon » in Ebisu, nº 26, p. 127-153.

Nanta Arnaud, 2002, « L'actualité du révisionnisme historique au Japon (2) » in Ebisu, no 27, p. 129-138.

Nanta Arnaud, 2002, «L'actualité du révisionnisme historique au Japon (3) » in Ebisu, no 28, p. 185-195.

Tosaka Jun 戸坂潤, 1935, Nihon ideorogi-ron - Gendai Nihon ni okeru nihonshugi, fashizumu, jiyūshugi, shisō no hihan 日本イデオロギー論— 現代日本に於ける日本主義・ファシズム・自由主義・思想の批 判 [Essai sur l'idéologie japonaise: critique des idées du nipponisme, du fascisme et du libéralisme dans le Japon contemporain], réédition en 1936 et augmentée en 1937, Hakuyōsha 白揚社, Tōkyō, 350 p.

Tsutsui Kiyotada 筒井清忠, 2006 [1996], Ni ni roku jiken to sono jidai Shōwaki Nihon no kōzō 二 ・二六事件とその時代一昭和期日本の構造 [L'Affaire du 26 février 1936 et son époque : structure du Japon de l'ère Shōwa], Chikuma gakugei bunkoちくま学芸文庫, Tōkyō, 418 p.

Tsutsur Kiyotada 筒井清忠, 2009, Konoe Fumimaro kyōyōshugi teki popyurisuto no higegi 近衛文麿教養主義的ポピュリストの悲劇 [Konoe Fumimaro la tragédie d'un populiste issu du culturalisme], Iwanami gendai bunko 岩波 現代文庫 \& Gakujutsu 学術, Tōkyō, 366 p.

YAMAGUCHI Yasushi 山口定, 2000, « Maruayama Masao to rekishi no mikata - Watakushi no mondai teiki » 丸山真男と歴史の見方一私の問題提起 [Maruyama Masao et la vision de l'histoire : ma formulation de la question] in Seisaku kagaku 政策科学 [Études politiques], nº 3, vol. 7, pp. 273-290.

Yosнiмото Takaki 吉本隆明, 1969a, «Kāru marukusu カール・マルクス [Karl Marx] », in Yoshimoto Takaaki zen chosaku-shū 吉本隆明全著作集, vol. 12, Keisō shobō 勁草書房, Tōkyō, pp. 97-268. 
Yosнiмото Takaaki 吉本隆明, 1969b, « Maruyama Masao-ron 丸山真男 論 (Essais sur Maruyama Masao), in Yoshimoto Takaaki zen chosaku-shū 吉 本隆明全著作集 [Recueil de l'ensemble des écrits de Yoshimoto Takaaki], vol. 12, Keisō shobō 勁草書房, Tōkyō, pp. 89-91.

Yosнiмото Takaaki 吉本隆明, 1969c, « Tenkō-ron 》転向論 (Essai sur le tenkō), in Yoshimoto Takaaki zen chosaku-shū 吉本隆明全著作集 [Recueil de l'ensemble des écrits de Yoshimoto Takaaki], vol. 13, Keisō shobō 勁草書房, Tōkyō, pp. 3-27.

Résumé : à partir de l'analyse du mécanisme exposé dans trois essais de Maruyama Masao sur la logique de l'ultranationalisme, les mouvements fascistes et la mentalité de leaders militaires japonais, trois grands principes ont pu être isolés dans notre étude : 1) l'assistance au tennō comme ciment patriotique de la Nation et manifestation d'un système d'aresponsabilité chez les élites ; 2) le rôle social central d'une partie des classes moyennes (les « petits tennō ») dans la diffusion du fascisme ; 3) les sources psychanalytiques de la violence de masse formulées en tant que « conservation de l'équilibre psychique par transfert du refoulement » de la violence entre Japonais et vers l'extérieur. Les raisons du succès des thèses de Maruyama présentées ensuite doivent cependant plus à sa capacité de synthétiser efficacement des lieux-communs préexistant et à sa périodisation originale du fascisme japonais qu'à ces trois principes. De nombreux intellectuels ont noté les limites de ces thèses. Nous avons finalement retenu Yoshimoto Taka.aki pour sa critique précoce de la représentation négative du peuple chez Maruyama, ainsi que Tsutsui Kiyotada, parce qu'il remarqua avec le plus de justesse les défauts du comparatisme Allemagne nazie/ Japon impérial et le caractère politique du discours des ultranationalistes négligé par Maruyama.

Mots-clés : essais sur le fascisme de Maruyama Masao, tennō, assistance au trône, ultranationalisme, périodisation du fascisme, semi-modernisation du Japon, comparatisme historique, Yoshimoto Taka.aki, peuple, Tsutsui Kiyotada 
Abstract: This article brings to light three underlying principles in Maruyama Masao's three well-known essays about ultra-nationalism logic, fascist movements and Japanese leaders mentality: 1) support to the emperor as a patriotic building block to the Nation national and as a manifestation of Japanese elites' "a-responsibility", 2) The key role of a part of the middle class, Maruyama named "small tennō", in the spread of fascism through society; 3) The psychonanalytic sources of mass violence "maintaining a mental balance through the transferring of the repression [of violence]", which is first aimed at the Japanese themselves, before being expanded onto others countries. The origins of the success of Maruyama's theses are not to befound in these principles, however, but rather in the efficient synthesis of pre-existing commonplace loci and in an original Japanese fascism "periodization" framework. Many intellectuals point out the limits in Maruyama's theses, but this article chooses to focus on two among them: 1) Yoshimoto Taka.aki for his early critic of Maruyama Masao's negative view of the masses; 2) Tsutsui Kiyotada for his accuracy in pointing out the flaws of a Nazi/Imperial Japan comparative analysis, and more precisely in pointing out the political dimension of ultranationalists arguments, overlooked by Maruyama.

Keywords: Maruyama Masao's fascism thesis, tennō, Imperial aid, ultranationalism, fascism evolution framework, half-modernized Japan, comparative historical studies, Yoshimoto Taka.aki, Masses, Tsutsui Kiyotada

キーワード：丸山真男の初期ファシズム論批判、大政翼賛、超国 家主義、日本ファシズムの時代区切り、日本の近代化批判、歴史比 較研究、吉本隆明、筒井清忠 